Gerión. Revista de Historia Antigua

ISSN: 0213-0181

https://dx.doi.org/10.5209/geri.74787

\title{
Alieni in Augusta Emerita: desde la fundación de la colonia hasta la promulgación de la Constitutio Antoniniana ${ }^{1}$
}

\author{
José Ortiz Córdoba ${ }^{2}$
}

Recibido: 27 de abril de 2020 / Aceptado: 19 de octubre de 2020

Resumen. Este trabajo pretende ofrecer una visión general sobre la inmigración de origen extrapeninsular domiciliada en Augusta Emerita a partir del análisis de la documentación epigráfica de la colonia. Estudiaremos aspectos como las regiones y ciudades de origen de estos inmigrantes, sus ocupaciones profesionales, las causas que determinaron su movilidad y la actividad que desarrollaron en Augusta Emerita tras su llegada. Cronológicamente nuestra contribución abarca el periodo comprendido entre la fundación de la colonia en el año 25 a.C. y la promulgación de la Constitutio Antoniniana a comienzos del siglo III d.C.

Palabras clave: inmigración; movilidad; alieni; Augusta Emerita; Hispania; epigrafía.

\section{[en] Alieni in Augusta Emerita: From the Foundation of the Colony until the Promulgation of the Constitutio Antoniniana}

\begin{abstract}
This work offers a general overview on immigration of extrapeninsular origin domiciled in Augusta Emerita from the analysis of the colony's epigraphic documentation. We will study aspects such as the regions and cities of origin of these immigrants, their professional occupations, the causes that determined their mobility and the activity they developed in Augusta Emerita after their arrival. Chronologically, our contribution covers the period between the foundation of the colony in 25 B.C. and the promulgation of the Constitutio Antoniniana in the early 3rd century AD.

Keywords: Immigration; Mobility; Alieni; Augusta Emerita; Hispania; Epigraphy.

Sumario: 1. Introducción. 2. La fundación y los primeros colonos. 2.1. Los colonos militares. 2.1.1. Los veterani quintani et decimani. 2.1.2 Veteranos de la legio $X X$. 2.1.3. Otros veteranos. 2.2. Los primeros habitantes: los gentilicios. 3. La inmigración posterior a la fundación. 3.1. Africanos. 3.2. Itálicos. 3.3. Orientales. 3.4. Galos. 4. Conclusiones. 5. Referencias bibliográficas.
\end{abstract}

Cómo citar: Ortiz Córdoba, J. (2021): Alieni in Augusta Emerita: desde la fundación de la colonia hasta la promulgación de la Constitutio Antoniniana, en Gerión 39/1, 167-196.

1 Este trabajo se enmarca dentro de las líneas de estudio del grupo de investigación HUM-215, dirigido por el Prof. Dr. C. González Román.

2 Universidad de Granada.

E-mail: joseortiz@ugr.es

ORCID: 0000-0003-3737-1115 


\section{Introducción}

La formación de la sociedad hispana en época republicana e imperial no puede entenderse sin la existencia de importantes corrientes migratorias que favorecieron la integración de la Península Ibérica en el mundo romano. Esta emigración se detecta desde el comienzo de la conquista y tuvo especial incidencia en las zonas inicialmente ocupadas de la costa mediterránea y de los valles del Ebro y el Baetis. Numéricamente su proyección debe considerarse como limitada, aunque conviene subrayar su trascendencia en cuanto a la incorporación de nuevas formas culturales y de explotación de los recursos. Esta primera emigración se yuxtapuso a los núcleos urbanos preexistentes, en algunos de los cuales se crearon estructuras jurídicas ajenas al mundo indígena, como los conventus Civium Romanorum que la tradición literaria documenta en varias ciudades del sur hispano. El progresivo avance de la conquista y la estabilización del dominio romano ayudaron al incremento de la inmigración. Ésta alcanzó su mayor volumen en el contexto de la colonización cesariana y augustea, que implicó el asentamiento de numerosos veteranos militares, principalmente de origen itálico. ${ }^{3}$ Este impulso colonizador facilitó la implantación del modelo de la civitas en el territorio provincial, favoreciendo, en consecuencia, la integración jurídica de la población emigrada. Con posterioridad, ya durante el Principado, observamos un notable aumento de la movilidad geográfica y una mayor diversidad en su composición. Junto a los itálicos detectamos ahora la presencia en Hispania de individuos de origen galo y africano, así como de gentes desplazadas desde Grecia, el Mediterráneo oriental, el Rin y el Danubio. ${ }^{4}$ Esta inmigración se concentró principalmente en los grandes centros urbanos, entre los que destacaron ciudades portuarias como Carthago Nova, Barcino u Olisipo, ${ }^{5}$ y, sobre todo, las capitales provinciales. ${ }^{6}$

Este trabajo pretende estudiar la inmigración de origen extrapeninsular domiciliada en Augusta Emerita, capital de Lusitania, abordando aspectos como su origen, su condición jurídica, las causas que determinaron la movilidad de sus protagonistas y el papel jugado por estos inmigrantes en su nueva ciudad. Cronológicamente nuestra contribución abarca el periodo comprendido entre la fundación de la colonia y la entrada en vigor de la Constitutio Antoniniana, cuya promulgación generó importantes cambios jurídicos que tuvieron su consecuente proyección en el ámbito onomástico, donde destaca la desaparición progresiva de la origo, un hecho que limita notablemente nuestro conocimiento sobre la movilidad geográfica en la Antigüedad tardía.

El concepto de movilidad que empleamos en nuestro trabajo viene marcado por mostrar un carácter de migración, es decir, de permanencia en el lugar de destino, lo que lo diferencia de otro tipo de movimientos de población que poseían un carácter temporal, dado que implicaban el retorno de sus protagonistas a su lugar de origen. La base fundamental de nuestro análisis está conformada por la documentación epigráfica, para cuya recopilación hemos empleado tres criterios: la mención de una

Brunt 1971, 259-265, 589-601 y 608-610; Keppie 1983, 49-86; Ortiz Córdoba 2019a, 69-531.

García y Bellido 1959, 119-154; Haley 1986, 137-175; 1991, 27-52; Gallego Franco 1997, 341-362; Beltrán

Fortes 2013, 185-204; Ortiz Córdoba 2019b, 155-201; 2019c, 1-22.

Ortiz Córdoba 2018, 115-122; 2020a, 41-67.

Edmondson 2004, 321-368; Melchor Gil 2006, 251-279; Ortiz Córdoba, 2020c, 980-1027. 
origo de carácter foráneo, ${ }^{7}$ la presencia en Augusta Emerita de tribus ajenas a los cives de la colonia, que fueron inscritos en la Papiria, ${ }^{8}$ y la detección de determinados nomina o cognomina que remiten a un horizonte no hispano. Su testimonio, en ausencia de origo, puede ayudarnos a identificar la presencia de población foránea en la ciudad, si bien es cierto que se trata de un criterio que debemos emplear con prudencia. ${ }^{9}$

\section{La fundación y los primeros colonos}

La fundación de Augusta Emerita se enmarca en el contexto de la guerra contra cántabros y astures. Sabemos por Dion Casio ${ }^{10}$ que tras la finalización de este conflicto Augusto decidió licenciar a los componentes más veteranos del ejército del norte, entre los que se encontraban algunos miembros de las legiones $V$ Alaudae y $X$ Gemina. Su desmovilización fue seguida de la fundación de una colonia situada a notable distancia del escenario de la guerra, en una zona despoblada junto al río Guadiana. El encargado de ejecutar los planes del Princeps fue el legatus Publius Carisius. La fecha tradicionalmente aceptada para la fundación colonial es la del año 25 a.C. ${ }^{11}$ Sin embargo, recientemente, el estudio de los Fasti Duovirales de la colonia ha venido a matizar ligeramente dicha cronología, sugiriendo la existencia, junto a la fecha tradicional, de otras dos opciones, el año 20 a.C., momento en que habrían tomado posesión los primeros duumviros electos, y el 24 a.C., la fecha considerada más probable por los autores del estudio. ${ }^{12}$ Estos datos deben complementarse con la información arqueológica, donde la cronología de los edificios más antiguos no sobrepasa el periodo 16-15 a.C., una circunstancia que ha llevado también a cuestionar la fecha tradicional del año 25 a.C. ${ }^{13}$ En nuestro caso consideramos que ninguno de estos planteamientos es incompatible con la aceptación de la cronología derivada de la tradición literaria. La deductio de una colonia era un proceso largo y complejo en el que intervenían elementos jurídicos y religiosos. Su implementación podía extenderse durante varios años y en muchas ocasiones se veía afectada por las circunstancias políticas o militares del momento. ${ }^{14}$ Por ello, aun aceptando que la decisión política de fundar la colonia se hubiese tomado en el 25 a.C., lo más probable es que la llegada de los colonos, la configuración del cuerpo cívico y el inicio de los trabajos de parcelación del territorio y de construcción del núcleo urbano hubiesen comenzado más tarde y abarcado un periodo de varios años. ${ }^{15}$ Por el contrario, lo que sí parece claro es que la fundación colonial no puede retrotraerse mucho más allá

\footnotetext{
Sobre la origo: Lassère 2005, 128-136; Grüll 2018, 139-150.

Wiegels 1985, 77.

Schulze 1966; Conway 1967; Kajanto 1982.

D.C. 53.26 .1$.

Brunt 1971, 593, nº 32; Forni 1982, 73; Le Roux 1982, 69-72; Saquete Chamizo 1997, 21-24; Edmondson 2018, 55-61; Ortiz Córdoba 2019a, 272-286.

12 Stylow - Ventura Villanueva 2009, 469-470. Asimismo, Ventura Villanueva 2009, 225-230.

Mateos Cruz 2001, 185-186.

14 Tres años es el plazo considerado normal por Keppie 1983, 87-100, a partir de los diversos casos recogidos en su obra. En Hispania el mejor ejemplo es el de la Colonia Genetiva Iulia, cuya deductio tuvo lugar entre los años 45-43 a.C.

15 Nogales Basarrate - Álvarez Martínez 2013, 56.
} 
de la fecha proporcionada por Dion Casio, puesto que la inscripción del sacrarium del teatro, ${ }^{16}$ realizada en el año CXXX de la colonia y que ha sido fechada a partir del 102 d.C. por la presencia del cognomen Dacicus en la onomástica de Trajano, impediría llevar la deductio más allá del 28 a.C. ${ }^{17}$ Se invalidarían así las propuestas de una posible fundación cesariana de la colonia realizadas por A. Canto. ${ }^{18}$

\subsection{Los colonos militares}

Augusta Emerita fue fundada mediante el asentamiento de varios contingentes de veteranos de las legiones $V$ Alaudae y $X$ Gemina. Su participación en la deductio aparece recogida en la obra de Dion $\operatorname{Casio}^{19}$ y se refleja también en las acuñaciones monetarias realizadas por la ciudad a partir del año 2 a.C. En ellas figura un águila legionaria situada entre dos estandartes que aparecen acompañados de los numerales $V$ y $X$, correspondientes a las dos unidades referidas. ${ }^{20}$ La aparición de ambas legiones en la documentación numismática contrasta, sin embargo, con su escasa presencia en la epigrafía de la colonia, donde fueron muy pocos los veteranos que señalaron esta condición en sus inscripciones. Esta circunstancia ha sido explicada de diferentes formas. Por un lado, aludiendo a la limitada difusión del hábito epigráfico en los momentos finales de la República; por otro, señalando el escaso interés de los veteranos por indicar su condición en ciudades compuestas mayoritariamente por soldados desmovilizados, ya que entre ellos existiría, a priori, una teórica igualdad social. ${ }^{21}$ A estas circunstancias, que podemos considerar generales del periodo y comunes a otras fundaciones hispanas, ${ }^{22}$ podríamos añadir un tercer elemento, propio en este caso de la colonia emeritense. Se trata del apoyo prestado por las legiones $V$ Alaudae y $X$ Gemina a la causa de M. Antonio, a cuyo lado combatieron en Actium. ${ }^{23}$ Tras esta derrota ambas unidades quedaron integradas en el ejército de Octaviano, que dispuso su traslado a la Península Ibérica para intervenir en la guerra del norte. Después de este conflicto los miembros más antiguos de ambas legiones fueron incluidos en el plan de desmovilización ideado por el Princeps. ${ }^{24}$ Sin embargo, frente a los veteranos de Augusto, que fueron asentados en poblaciones itálicas, los antiguos soldados de Antonio recibieron tierras en regiones periféricas del Imperio, donde su presencia no pudiera significar una amenaza. ${ }^{25} \mathrm{Un}$ ejemplo de esta forma de actuar pudo haber sido Augusta Emerita, donde los colonos asentados habrían optado por omitir en la epigrafía su antigua vinculación con Antonio. ${ }^{26}$ Esta circunstancia, que también ha sido propuesta para Pax Iulia,${ }^{27}$ contrasta con la

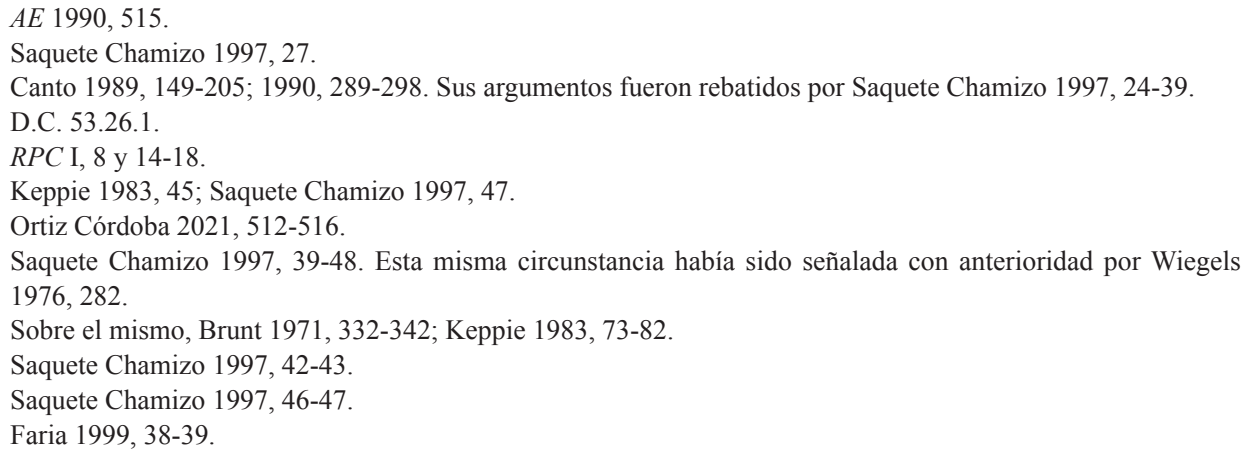


existente en otras fundaciones hispanas, como Caesar Augusta, Tucci o Astigi, cuyos colonos sí hicieron constar el nombre de sus antiguas unidades.

\subsubsection{Los veterani quintani et decimani}

Los veterani quintani et decimani apenas han dejado rastro en la epigrafía emeritense. En ella no se registra ninguna mención a la legio $V$, una unidad que, en cualquier caso, apenas aparece en la epigrafía hispana, siendo uno de los pocos testimonios conocidos el del tribunus militum L. Blattius Ventinus en Hispalis. ${ }^{28}$ Tampoco es mucho mejor el panorama que ofrece la epigrafía de la X Gemina, aunque en esta ocasión sí contamos con varios epígrafes que podemos relacionar con la deductio emeritense. Sería el caso de las inscripciones funerarias de P. Cincius Rufus y de P. Talius. La primera de ellas fue encontrada en la catedral de Badajoz. ${ }^{29}$ Es probable que hubiese formado parte de una sepultura familiar, puesto que junto a Cincius Rufus aparece también su hijo, $P$. Cincius Tuscus, que fue el encargado de levantar la inscripción. Su datación en época augustea, probablemente a comienzos del siglo I d.C., permitiría incluir a Cincius Rufus entre los veteranos asentados en Augusta Emerita en el año 25 a.C., aunque no se trata de una opinión unánime en la historiografía. ${ }^{30}$ En favor del origen foráneo de este miles jugaría también su onomástica, puesto que su gentilicio, de posible ascendencia etrusca, es muy escaso en Hispania. ${ }^{31}$

Circunstancias similares pueden aducirse en el caso de P. Talius, ${ }^{32}$ cuya inscripción, actualmente perdida, fue hallada probablemente en el territorio de Metellinum. La ausencia de cognomen en la onomástica de este miles de la legio X sería un indicativo de la antigüedad de su inscripción, que podría situarse en época augustea. ${ }^{33} \mathrm{Su}$ gentilicio parece tener también raíz etrusca y su presencia constituye un unicum en la epigrafía hispana. ${ }^{34}$ En función de los datos expuestos, J. Edmondson planteó la posibilidad de que $P$. Talius hubiese formado parte del contingente de colonos establecidos en la fundación de Augusta Emerita, por lo que podría tratarse de un veteranus de la legio $X$, aunque esta condición no se encuentra indicada en el texto epigráfico. Su vinculación con la colonia emeritense no ofrece dudas, ya que Talius pertenecía a la tribu Papiria. Sin embargo, resulta curioso que su inscripción, de carácter funerario, proceda del ager de Metellinum, una circunstancia que quizás podamos vincular con la existencia de un traslado posterior a su asentamiento. ${ }^{35}$

28 CIL II 1176. Recientemente ha sido vinculada con esta unidad una pequeña estatua broncínea encontrada en "Los Columbarios". Representa a un legionario que luce un penacho transversal sobre su cimera, a modo de cresta, una de las características físicas propias de las alondras, significado del sobrenombre Alaudae que porta la legio $V$. Representaciones de cimeras similares a la de esta estatuilla se observan también en algunas de las primeras acuñaciones emeritenses (RIC 7a-b). Al respecto, Paredes Martín 2018, 107-119.

29 CIL II 1016: P(ublio) Cincio Pap(iria) Ruf(o, -ino) / A(ugustano) m(iliti) leg(ionis) X / P(ublius) Cincius Pap(iria) Tuscus / patri suo et sibi / per se d(e) s(uo) f(aciendum) c(uravit).

30 Es considerado colono fundador por Forni 1976, 37-38; Le Roux 1982, 173; Keppie 2000, 90, mientras que Edmondson 2010, 248-249, se muestra prudente. Para Hernández Guerra 1999, 20, podría ser hijo de uno de los veteranos asentados en el 25 a.C.

31 Schulze 1966, 266 y 318; Abascal Palazón 1994, 111.

32 HEp 4, 1994, 186: P(ublius) Talius Q(uinti) f(ilius) / Pap(iria) leg(ionis) Xh(ic) s(itus) e(st) s(it) t(ibi) t(erra) l(evis).

33 Edmondson 2010, 21. Hernández Guerra 1999, 36, la fecha entre los años 37 y 63 d.C.

34 Schulze 1966, 94, n. 8 y 425; Navarro Caballero - Ramírez Sádaba 2003, 312.

35 Recio Veganzones - Curbera 1996, 15; Edmondson 2010, 217-218. 
También podría relacionarse con la deductio colonial, aunque de forma indirecta, la inscripción de [? P(ublius)? Iustul]enus Aper, que sirvió en la X Gemina durante el siglo I d.C., probablemente cuando esta unidad estuvo destinada en Panonia y Germania. ${ }^{36}$ Tras retirarse habría optado por volver a su ciudad natal, donde falleció a los 65 años en un momento posterior a la muerte de Domiciano, ya que la presencia de los epítetos Pia y Fidelis en el nombre de la legión nos ofrece ese momento como terminus post quem. Su pertenencia a la tribu Papiria y la origo Aug(ustanus), una forma poco frecuente de designar a los ciudadanos de Augusta Emerita, lo vinculan claramente con esta colonia. No obstante, su gentilicio con el añadido de un sufijo en - enus sugiere una ascendencia foránea. Por ello no sería extraño que nos encontrásemos ante el descendiente de alguno de los colonos itálicos asentados en Mérida. ${ }^{37}$ De esta manera, su servicio en la legio $X$, una de las unidades fundadoras de la colonia, reflejaría los lazos establecidos entre la comunidad emeritense y esta legión, de forma similar a lo que ocurre, por ejemplo, en el caso de Augusta Gemella Tucci.

\subsubsection{Veteranos de la legio $X X$}

Contamos también para esta primera etapa de la colonia emeritense con varias inscripciones que mencionan a la legio $X X$. Estos epígrafes, de fecha muy temprana, fueron el principal argumento esgrimido por A. Canto para proponer la existencia de un praesidium cesariano y de dos deductiones coloniales en época de Augusto, en la primera de las cuales habría tomado parte la legio $X X .^{38}$ Esta interpretación se apoya en la posible presencia de esta unidad en Hispania en los años anteriores a la batalla de Actium y en su participación en la guerra del norte, posibilidad recogida por diversos autores ${ }^{39}$ y rebatida por S. Perea, para quien esta legión nunca estuvo en la Península Ibérica. ${ }^{40} \mathrm{La}$ existencia de un asentamiento de veteranos de la legio $X X$ con anterioridad al año 25 a.C. ha sido rechazada por diversos autores al considerar que no existen testimonios directos, más allá de estas inscripciones, que así lo indiquen. Sin embargo, estos mismos autores no descartan la posibilidad de que algunos miembros de esta unidad se hubieran establecido voluntariamente en la ciudad tras finalizar su servicio o que incluso se hubiesen beneficiado de algunos de los sucesivos repartos de tierra realizados tras la fundación. ${ }^{41}$

Sea como sea, la realidad es que conocemos la presencia de tres miembros de la legio XX en los momentos iniciales de Augusta Emerita..$^{42}$ Dos de ellos se documentan en la inscripción CIL II 22, procedente de Elvas, localidad portuguesa que habría pertenecido al territorium emeritense..$^{43}$ Conforma un monumento funerario datado

36 AE 2006, 615: [? P(ublius)?Iustul]/enus P(ubli) f(ilius) / Pap(iria tribu) Aper / Aug(ustanus) veter(anus) / leg(ionis) X Gem(inae) / P(iae) F(idelis) an(norum) LXV/h(ic) s(itus) e(st) s(it) t(ibi) t(erra) l(evis).

Edmondson - Hidalgo Martín 2007, 488.

Canto 1989, 170-171 y 197; 1990, 292 y 294.

Roldán Hervás 1974, 208; Le Roux 1982, 59; Rodríguez González 2001, 391-392; Malone 2005, 321-323.

Perea Yébenes 2000, 581-587.

Wiegels 1976, 272; Le Roux 1982, 59-60; Saquete Chamizo 1997, 63.

42 A ellos debemos añadir un cuarto testimonio de esta unidad que sería posterior a la deductio, ya que ha sido fechado entre finales del siglo I y comienzos del II d.C. Aunque procede de Norba Caesarina, la tribu Papiria que porta este legionario, de onomástica desconocida, lo relaciona con Augusta Emerita (CIL II 719).

43 CIL II 22: C(aius) Axonius Q(uinti) f(ilius) Pap(iria) / leg(ionis) XX nat(us) col(onia) / Fir(mo) Piceno se vivo / moniment(um) fec(it) sibi et / fr(atri) Q(uinto) Ax(onio) Q(uinti) f(ilio). 
entre los años 25 a.C. y 25 d.C. ${ }^{44}$ que C. Axonius, natural de Firmum Picenum y miles de la legio $X X$, levantó para sí mismo y para su hermano Quintus. En la inscripción no consta que este último fuera militar, aunque el hecho de que aparezca enterrado junto a su hermano en un lugar tan alejado de su tierra natal podría indicar que lo habría acompañado hasta allí como miembro de la misma unidad. ${ }^{45}$ Desconocemos si $C$. Axonius, el único de los hermanos que acredita su condición militar, falleció en activo o se estableció en Augusta Emerita en calidad de veterano, hipótesis esta última por la que se han decantado E. W. Haley y J. Edmondson y que nosotros consideramos también como la más probable. ${ }^{46}$ En favor de esta propuesta se encontraría su pertenencia a la tribu Papiria, que no se corresponde con la Velina propia de los cives de Firmum Picenum. ${ }^{47}$ Esta modificación de tribu indicaría la existencia de un cambio en el lugar de residencia de este personaje, que probablemente habría recibido tierras en la parte occidental del ager de Augusta Emerita. ${ }^{48}$

El tercer miembro conocido de esta unidad es el veteranus L. Hermelius, cuya inscripción procede también del ager colonial. ${ }^{49}$ Sirvió en la legio $X X$ en época augustea, circunstancia que ha permitido situar su reclutamiento en el periodo 44-30 a.C. y su desmovilización entre el último cuarto del siglo I a.C. y el cambio de Era. ${ }^{50}$ En la onomástica del difunto destacan tanto la ausencia de cognomen, signo de la antigüedad de la pieza, como la presencia del gentilicio Hermelius, un nomen etrusco no atestiguado en Hispania. ${ }^{51}$ Esta peculiaridad onomástica, junto a la cronología de la inscripción, llevó a P. Le Roux a plantear la posibilidad de que nos encontrásemos ante uno de los primeros veteranos deducidos en Augusta Emerita, circunstancia que reforzaría su pertenencia a la tribu Papiria. Habría sido inscrito en ella tras su instalación en la colonia, en cuyo territorium recibió posiblemente una parcela de tierra. ${ }^{52}$

\subsubsection{Otros veteranos}

A los ejemplos anteriores podríamos añadir otros dos casos. El más destacado es el de C. Voconius ${ }^{53}$ cuya inscripción, fechada a mediados del siglo I d.C., procede de la tumba de los Voconios, situada en la necrópolis de "Los Columbarios". Se trata de una tumba monumentalizada donde fueron depositados los restos de varios miembros de una misma familia. Los hallazgos realizados en la zona permiten suponer que C. Voconius habría sido enterrado junto a su esposa Caecilia Anus en una primera sepultura que posteriormente fue ampliada por su hijo, C. Voconius Proculus, mediante la construcción de un mausoleo que debía acoger también su tumba y la

\footnotetext{
Edmondson 2010, 247.

Le Roux 1982, 59-60.

Haley 1986, 138; Edmondson 2010, 247.

Kubistschek 1972 [1889], 64.

Le Roux 1982, 59; Malone 2005, 221; Edmondson 2010, 247.

CIL II 662: L(ucius) Hermelius / L(uci) f(ilius) Pap(iria) vet(eranus) leg(ionis) / XX / _ - . - - ? .

Le Roux 1982, 60; Edmondson 2010, 248.

Schulze 1966, 173 y 458.

Le Roux 1982, 60. Tampoco descartaba la posibilidad de que L. Hermelius fuese un civis Emeritensis enrolado en la legio $X X$ que hubiese retornado a su ciudad natal tras su servicio.

53 AE 2000, 691: C(aio) Voconio C(ai) f(ilio) Pap(iria) patri / Caeciliae Anui matri / Voconiae C(ai) f(iliae) Mariae sorori / C(aius) Voconius C(ai) f(ilius) Proculus fecit.
} 
de su hermana. ${ }^{54}$ Es posible que esa ampliación hubiera conllevado la realización de una nueva inscripción funeraria de mármol, la que conservamos actualmente, donde fueron inscritos los nombres de los cuatro personajes enterrados en el mausoleo. Esta placa vendría a sustituir a una estela anterior de granito, mucho más modesta, en la que únicamente habrían figurado los nombres de C. Voconius y su esposa y la indicación de las dimensiones de la tumba. ${ }^{55}$ En la parte superior de la nueva inscripción $C$. Voconius Proculus hizo grabar las condecoraciones militares obtenidas por su padre, entre las que podemos observar dos armillae, dos torques y varias phalerae. Aunque la inscripción no incluye ninguna mención sobre su unidad, la presencia de estas recompensas acreditan la condición militar de C. Voconius pater, que, de hecho, ha sido identificado como uno de los veteranos establecidos durante la deductio emeritense. ${ }^{56}$ Estaríamos, por tanto, ante las dos primeras generaciones de una familia relacionada con la fundación colonial, una circunstancia que seguramente C. Valerius Proculus quiso enfatizar cuando mandó grabar en su epitafio los premios militares obtenidos por su padre. El origen de esta familia debe buscarse en la Península Itálica, posiblemente en la ciudad de Aricia, ubicada en el Latium, región donde el nomen Voconius resulta frecuente.$^{57}$ Por el contrario, su presencia en Hispania es limitada y se concentra fundamentalmente en Lusitania y en la Citerior. ${ }^{58}$

En este apartado también podríamos incluir a $C$. Salvius, cuya inscripción remite a la primera mitad del siglo I d.C. ${ }^{59}$ Conforma una estela funeraria de cabecera semicircular en la que destaca la presencia del término cornice[n]. J. L. Ramírez Sádaba, primer editor de la pieza, lo identificó como el cognomen del difunto, ${ }^{60}$ aunque J. GómezPantoja consideró que este vocablo aludiría más bien a la profesión de C. Salvius, que este autor relacionó, aunque de manera conjetural, con la actividad del anfiteatro, donde los músicos tenían un papel destacado en el desarrollo de los ludi ${ }^{61}$ La hipótesis del oficio es también seguida por J. Edmondson, aunque planteando en este caso que Salvius hubiese pertenecido al personal de los IIviri emeritenses o incluso, en calidad de cornicen militar, al equipo del gobernador provincial. Este mismo autor sugiere también la posibilidad de que nos encontremos ante uno de los colonos deducidos en Augusta Emerita o ante uno de sus descendientes inmediatos. ${ }^{62}$ Respaldaría esta propuesta, además del oficio de cornice [n] desarrollado por C. Salvius, muy vinculado al ámbito militar, la ausencia de cognomen en su onomástica, un rasgo propio de las primeras generaciones de colonos emeritenses. A estos elementos podríamos añadir la indicación de la pedatura, una costumbre de tradición itálica que también habría estado presente en la primera estela de la tumba de C. Voconius.

54 Sobre el mausoleo de los Voconii: Bendala Galán 1972, 224-229, 235-236 y 240-253; Márquez Pérez 2006, 101-114.

55 AE 2010, 673: C(aius) V[oconius C(ai) f(ilius) Pap(iria)] / Ca[ecilia Anus] / in [f(ronte) p(edes) XII in agro p(edes) X]. Al respecto, Márquez Pérez 2006, 102-103; Ramírez Sádaba 2010, 325-327; Pardo Anta 2017, 42 y 184.

56 Saquete Chamizo 1997, 63-64; Ramírez Sádaba 2010, 326-327; Edmondson 2010, 221; Pardo Anta 2017, 184 y 219 .

57 Conway 1967, 591; Ramírez Sádaba 2010, 327.

58 Abascal Palazón 1994, 250; Navarro Caballero - Ramírez Sádaba 2003, 346.

59 AE 2006, 595: C(aius) Salvius Q(uinti) / f(ilius) Pap(iria) Cornice[n] / hic sit(us) est in / [f]r(onte) p(edes) XII in $\operatorname{agr}(o) / p$ (edes) $X$.

60 Ramírez Sádaba 1994-1995, 266-267.

${ }^{61}$ Gómez-Pantoja 2009, 33, no 44.

62 Edmondson 2006, 137. 


\begin{tabular}{|c|c|c|c|c|c|c|}
\hline Onomástica & Cron. & Origo & Tribu & $\begin{array}{l}\text { Lugar de } \\
\text { hallazgo }\end{array}$ & $\begin{array}{c}\text { Función } \\
\text { Social }\end{array}$ & Referencia \\
\hline $\begin{array}{l}\text { Caius } \\
\text { Axonius }\end{array}$ & $\begin{array}{c}\text { Reinados de } \\
\text { Augusto o } \\
\text { Tiberio }\end{array}$ & $\begin{array}{l}\text { Firmum } \\
\text { Picenum }\end{array}$ & Papiria & Elvas & $\begin{array}{c}\text { Miles } \\
\text { legionis XX }\end{array}$ & CIL II 22 \\
\hline $\begin{array}{l}\text { Quintus } \\
\text { Axonius }\end{array}$ & $\begin{array}{c}\text { Reinados de } \\
\text { Augusto o } \\
\text { Tiberio }\end{array}$ & $\begin{array}{l}\text { Firmum } \\
\text { Picenum }\end{array}$ & & Elvas & $\begin{array}{c}\text { ¿Miles } \\
\text { legionis } \\
X X ?\end{array}$ & CIL II 22 \\
\hline $\begin{array}{c}\text { Publius } \\
\text { Cincius } \\
\text { Rufus }\end{array}$ & $\begin{array}{c}\text { Época } \\
\text { augustea }\end{array}$ & $\begin{array}{l}\text { Augustanus. } \\
\text { Ascendencia } \\
\text { itálica }\end{array}$ & Papiria & Badajoz & $\begin{array}{c}\text { Miles } \\
\text { legionis X; } \\
\text { ¿Veteranus? }\end{array}$ & CIL II 1016 \\
\hline $\begin{array}{c}\text { Lucius } \\
\text { Hermelius }\end{array}$ & $\begin{array}{c}\text { Época } \\
\text { augustea }\end{array}$ & $\begin{array}{c}\text { Posible } \\
\text { origen itálico }\end{array}$ & Papiria & $\begin{array}{l}\text { Villamejía } \\
\text { (Cáceres) }\end{array}$ & $\begin{array}{l}\text { Veteranus } \\
\text { legionis } X X\end{array}$ & CIL II 662 \\
\hline $\begin{array}{c}\text { [? P(ublius)? } \\
\text { Iustul]enus } \\
\text { Aper }\end{array}$ & $\begin{array}{c}\text { Transición } \\
\text { ss. I al II d.C. }\end{array}$ & $\begin{array}{l}\text { Augustanus. } \\
\text { Descendiente } \\
\text { de itálicos }\end{array}$ & Papiria & Mérida & $\begin{array}{c}\text { Veteranus } \\
\text { legionis X } \\
\text { Geminae } \\
\text { Piae Fidelis }\end{array}$ & $\begin{array}{l}A E 2006, \\
\quad 615\end{array}$ \\
\hline Caius Salvius & Siglo I d.C. & $\begin{array}{c}\text { Posible } \\
\text { origen itálico }\end{array}$ & Papiria & Mérida & Cornicen & $\begin{array}{c}A E 2006, \\
595\end{array}$ \\
\hline $\begin{array}{c}\text { Publius } \\
\text { Talius }\end{array}$ & $\begin{array}{c}\text { Época } \\
\text { augustea }\end{array}$ & $\begin{array}{c}\text { Posible } \\
\text { origen itálico }\end{array}$ & Papiria & $\begin{array}{c}\text { Villanueva } \\
\text { de la Serena } \\
\text { (Badajoz) }\end{array}$ & $\begin{array}{c}\text { Miles } \\
\text { legionis X }\end{array}$ & $\begin{array}{c}H E p 4, \\
1994,186\end{array}$ \\
\hline $\begin{array}{c}\text { Caius } \\
\text { Voconius }\end{array}$ & $\begin{array}{l}\text { Primera } \\
\text { mitad s. I } \\
\text { d.C. }\end{array}$ & $\begin{array}{c}\text { Posible } \\
\text { origen itálico }\end{array}$ & Papiria & Mérida & Veteranus & $\begin{array}{c}A E 2000, \\
691 \\
A E 2010 \\
673\end{array}$ \\
\hline
\end{tabular}

Tabla 1. Veteranos militares relacionados con la deductio de Augusta Emerita

\subsection{Los primeros habitantes: los gentilicios}

Para completar el panorama sociológico de los primeros momentos de Augusta Emerita debemos recurrir a la onomástica. En ella encontramos una serie de gentilicios poco frecuentes en Hispania que podemos relacionar con la emigración itálica. Esta circunstancia ha sido estudiada, para el caso de Lusitania, por M. Navarro Caballero, que destacó la presencia en la región de un grupo de nomina de origen itálico y escasa difusión en el ámbito provincial a los que calificó como "gentilicios fósiles". ${ }^{63}$ $\mathrm{Su}$ escaso volumen contrasta con la notable expansión de otros gentilicios como Iulius, Valerius, Cornelius, etc., tras los cuales podemos suponer que se encontraban numerosos indígenas latinizados. También J. Edmondson ha puesto el acento sobre esta cuestión, señalando la presencia en la primera epigrafía colonial de un numeroso grupo de nomina que remitirían a un horizonte itálico y que podríamos relacionar con los primeros habitantes de la ciudad o con sus descendientes inmediatos. ${ }^{64}$ Una circunstancia similar hemos podido constatar en nuestra tesis doctoral, donde hemos identificado también un importante grupo de gentilicios, ubicados principalmente

\footnotetext{
Navarro Caballero 2000, 281-298.

64 Edmondson 2006, 110-121; 2018, 62-63.
} 
en el ager Emeritensis, que consideramos podrían vincularse a los primeros colonos itálicos o a sus descendientes inmediatos y que detallamos en la siguiente tabla: ${ }^{65}$

\begin{tabular}{|c|c|c|c|c|c|}
\hline Onomástica & Cron. & Domicilio & Tribu & $\begin{array}{l}\text { Lugar de } \\
\text { hallazgo }\end{array}$ & Referencia \\
\hline Lucius Arruntius & $\begin{array}{l}\text { Comienzos s. } \\
\text { I d.C. }\end{array}$ & $\begin{array}{l}\text { Praefectura } \\
\text { Turgaliensis }\end{array}$ & Papiria & $\begin{array}{l}\text { Puerto de Santa } \\
\text { Cruz (Cáceres) }\end{array}$ & CILC II, 655 \\
\hline $\begin{array}{c}\text { Quintus Artorius } \\
\text { Vetus }\end{array}$ & Siglo I d.C. & $\begin{array}{l}\text { Praefectura } \\
\text { Turgaliensis }\end{array}$ & Papiria & $\begin{array}{l}\text { Herguijuela } \\
\text { (Cáceres) }\end{array}$ & CILC II, 522 \\
\hline $\begin{array}{l}\text { [-] Cornelius } \\
\text { Gallus }\end{array}$ & Siglo I d.C. & $\begin{array}{c}\text { Ager } \\
\text { Emeritensis }\end{array}$ & Papiria & $\begin{array}{c}\text { Elvas (Portalegre, } \\
\text { Portugal) }\end{array}$ & CIL II 5216 \\
\hline $\begin{array}{c}\text { Quintus } \\
\text { Cornelius } \\
\text { Montanus }\end{array}$ & Siglo I d.C. & $\begin{array}{l}\text { Praefectura } \\
\text { Turgaliensis }\end{array}$ & Papiria & $\begin{array}{l}\text { Campo Lugar } \\
\text { (Cáceres) }\end{array}$ & CILC II, 467 \\
\hline $\begin{array}{c}\text { Publius Curtius } \\
\text { Italicus }\end{array}$ & $\begin{array}{l}\text { Transición ss. } \\
\text { I al II d.C. }\end{array}$ & $\begin{array}{l}\text { Augusta } \\
\text { Emerita }\end{array}$ & Papiria & Mérida & $\begin{array}{c}\text { HEp } 5,1995, \\
93\end{array}$ \\
\hline Titus Etrilius & $\begin{array}{c}\text { Primera } \\
\text { mitad s. I d.C. }\end{array}$ & $\begin{array}{l}\text { Augusta } \\
\text { Emerita }\end{array}$ & Papiria & Mérida & $A E 2006,614$ \\
\hline Marcus Iunius & $\begin{array}{l}\text { Primera } \\
\text { mitad s. I } \\
\text { d.C. }\end{array}$ & $\begin{array}{l}\text { Praefectura } \\
\text { Turgaliensis }\end{array}$ & Papiria & $\begin{array}{l}\text { Madrigalejo } \\
\text { (Cáceres) }\end{array}$ & CILC II, 624 \\
\hline $\begin{array}{c}\text { Quintus } \\
\text { Sertorius Balbus }\end{array}$ & & $\begin{array}{l}\text { Praefectura } \\
\text { Turgaliensis }\end{array}$ & Papiria & Trujillo (Cáceres) & CILC II, 751 \\
\hline $\begin{array}{c}\text { Quintus Servilius } \\
\text { Celer }\end{array}$ & $\begin{array}{l}\text { Mediados s. } \\
\text { I d.C. }\end{array}$ & $\begin{array}{l}\text { Praefectura } \\
\text { Turgaliensis }\end{array}$ & Papiria & $\begin{array}{l}\text { La Herguijuela } \\
\text { (Cáceres) }\end{array}$ & CILC II, 523 \\
\hline $\begin{array}{c}\text { Quintus Sevius } \\
\text { Firmanus }\end{array}$ & & $\begin{array}{c}\text { Ager } \\
\text { Emeritensis }\end{array}$ & Papiria & $\begin{array}{l}\text { São Miguel de } \\
\text { Mota (Évora) }\end{array}$ & CIL II 139 \\
\hline Quintus Tallius & $\begin{array}{c}\text { Época } \\
\text { augustea }\end{array}$ & $\begin{array}{c}\text { Civitas } \\
\text { Igaeditanorum }\end{array}$ & Papiria & $\begin{array}{c}\text { Idanha-a-Velha } \\
\text { (Portugal) }\end{array}$ & $\begin{array}{c}\text { HEp } 18 \\
2009,563\end{array}$ \\
\hline $\begin{array}{c}\text { Lucius } \\
\text { Tussanius Rufus }\end{array}$ & $\begin{array}{l}\text { Mediados s. } \\
\text { I d.C. }\end{array}$ & $\begin{array}{l}\text { Praefectura } \\
\text { Turgaliensis }\end{array}$ & Papiria & Trujillo (Cáceres) & CILC II, 839 \\
\hline $\begin{array}{c}\text { Marcus Vibius } \\
\text { Rufus } \\
\end{array}$ & $\begin{array}{l}\text { Transición ss. } \\
\text { I al II d.C. }\end{array}$ & $\begin{array}{l}\text { Praefectura } \\
\text { Turgaliensis }\end{array}$ & Papiria & $\begin{array}{l}\text { Alcollarín } \\
\text { (Cáceres) }\end{array}$ & CILC II, 446 \\
\hline $\begin{array}{c}\text { Marcus Victorius } \\
\text { Galba }\end{array}$ & Siglo I d.C. & $\begin{array}{l}\text { Praefectura } \\
\text { Turgaliensis }\end{array}$ & Papiria & $\begin{array}{l}\text { Madrigalejo } \\
\text { (Cáceres) }\end{array}$ & CILC II, 615 \\
\hline $\begin{array}{l}\text { Lucius } \\
\text { Vocconius }\end{array}$ & $\begin{array}{l}\text { Mediados s. } \\
\text { I d.C. }\end{array}$ & $\begin{array}{l}\text { Praefectura } \\
\text { Turgaliensis }\end{array}$ & Papiria & $\begin{array}{l}\text { Puerto de Santa } \\
\text { Cruz (Cáceres) }\end{array}$ & CILC II, 666 \\
\hline
\end{tabular}

Tabla 2. Posibles colonos o descendientes de colonos relacionados con la deductio de Augusta Emerita

65 Debido al notable volumen de documentación epigráfica en esta zona de la colonia hemos incluido en esta tabla únicamente los habitantes del territorio emeritense que, además de un gentilicio de ascendencia itálica, señalan su pertenencia a la tribu Papiria, que los vincula directamente con el censo ciudadano de Augusta Emerita. Sobre los gentilicios itálicos en el ager Emeritensis, Gómez Santa Cruz 2017, 499-522. 


\section{La inmigración posterior a la fundación}

Tras la fundación de la colonia la documentación epigráfica certifica la existencia de una continua afluencia de inmigrantes no hispanos hacia Augusta Emerita, dinámica en la que sin duda influyó su designación como capital provincial. Estos inmigrantes presentan una notable variedad de orígenes, como exponemos a continuación.

\subsection{Itálicos}

El grupo más numeroso de inmigrantes no hispanos documentados en Augusta Emerita con posterioridad a la deductio está compuesto por la población de origen itálico. Cronológicamente, los testimonios más antiguos de este colectivo remiten al siglo I d.C. y corresponden a las inscripciones de los milites M. Furius Flo[rus?] y M. Tavonius Firmus. El epígrafe del primero de ellos presenta problemas de lectura derivados de la pérdida de la parte final del texto y de algunos trozos de su lateral derecho. ${ }^{66}$ Estas lagunas afectan a datos tan importantes como el cognomen de este legionario, que sólo se conserva parcialmente, sus años de muerte y servicio o la identidad de los dedicantes de la inscripción. ${ }^{67}$ Pese a estos problemas, P. Le Roux consideró que nos encontraríamos ante un miembro de la I Adiutrix, ${ }^{68}$ la legión reclutada por Nerón entre los marineros de la classis Misenensis en los primeros meses del año 68 para hacer frente a los levantamientos provinciales que amenazaban su poder. ${ }^{69}$ La presencia de M. Furius Flo[rus?] en Augusta Emerita se explicaría como consecuencia de los movimientos de tropas que tuvieron lugar durante la guerra civil del 69 d.C., ya que la I Adiutrix fue enviada a Hispania por Vitelio en la primavera de ese año con el objetivo de hacerse con el control de los yacimientos de metales preciosos, principalmente de oro, existentes en la Península..$^{70}$ Desconocemos dónde fue acantonada esta legión durante su estancia en Hispania, aunque P. Le Roux propuso que habría pasado este periodo acampada junto a Augusta Emerita, una situación que permitiría explicar el fallecimiento de este legionario en la capital lusitana. ${ }^{71}$ Su muerte habría tenido lugar mientras se encontraba en activo, aunque por desgracia no conocemos la edad ni tampoco los años de servicio de Flo[rus(?)]. En cambio, sí se ha conservado su origo, indicada mediante la expresión natione Italicus, una fórmula que no permite precisar mucho sobre el lugar de origen de este legionario, pese a lo cual algunos autores lo han vinculado con la región de los sabinos. ${ }^{72} \mathrm{Su}$ pertenencia a la I Adiutrix permite fechar esta inscripción entre los años 69-70 d.C., periodo en que la unidad permaneció estacionada en Hispania. ${ }^{73}$

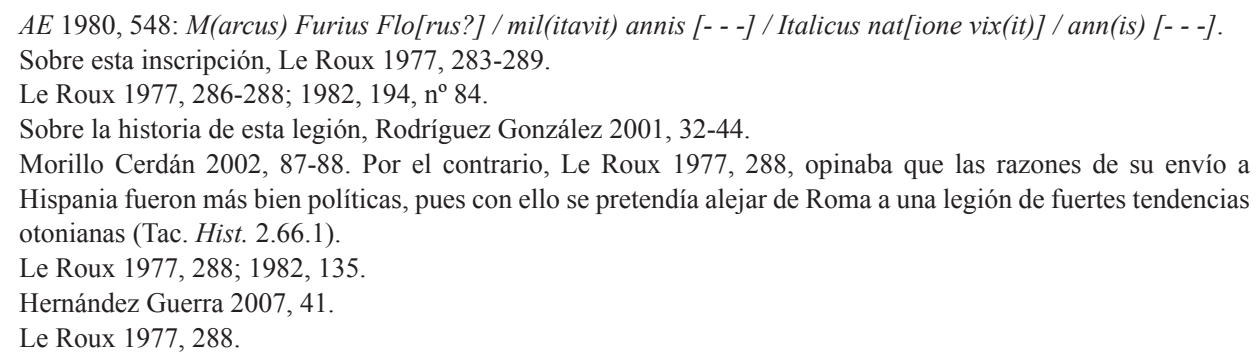


Bastante más precisos podemos ser en el caso de M. Tavonius Firmus, cuya origo indica claramente su vinculación con la ciudad itálica de Ateste ${ }^{74}$ una relación que se ve reforzada por su pertenencia a la tribu Romilia, propia de los habitantes de esta localidad. ${ }^{75}$ Firmus sirvió en las filas de la legio VI Victrix durante la primera mitad del siglo I d.C., probablemente entre los reinados de Calígula y Claudio. ${ }^{76} \mathrm{Su}$ muerte tuvo lugar mientras se encontraba en activo, ya que apenas acredita once años de servicio, indicados con el término aera,$^{77}$ y su edad de fallecimiento, treinta años, es bastante baja. Su inscripción no indica las causas que motivaron su presencia en Augusta Emerita, aunque quizás podamos relacionar su llegada a esta ciudad con el desarrollo de tareas administrativas en el officium del gobernador provincial. ${ }^{78}$

Al siglo II d.C. correspondería el epitafio del veteranus L. Avercius Celer, que ha sido dado a conocer recientemente. ${ }^{79}$ Este antiguo miembro de la legio VII Gemina fue homenajeado por su hermano L. Avercius Maxsimus, veterano de la misma unidad. El texto, inscrito sobre una placa de mármol blanco, presenta una ordinatio bastante descuidada y omite algunos datos importantes como la edad del difunto. Pese a ello, la información que proporciona resulta sumamente interesante en cuanto al origen de estos veteranos, que debemos situar en la ciudad centroitálica de Peltuinum, citada en la inscripción como origo de L. Avercius Celer. De él sabemos también que pertenecía a la tribu Quirina, propia de los ciudadanos de este municipio. ${ }^{80}$ Ambos elementos, origo y tribu, serían extensibles a su hermano, que presenta la peculiaridad de portar el mismo praenomen que el difunto, un hecho que, aunque curioso, resulta común en el siglo II d.C. y contó al parecer con una cierta proyección en Peltuinum. ${ }^{81}$ Por el contrario, la inscripción no contiene ninguna información sobre las razones que llevaron a ambos hermanos a fijar su residencia en la capital de Lusitania. No obstante, podemos suponer que, al igual que otros veteranos de esta unidad, pudieron haber desempeñado tareas administrativas en Augusta Emerita, optando finalmente por establecerse allí, o que, simplemente, eligieron para su retiro una ciudad populosa que ejerció una notable capacidad de atracción sobre los veteranos del ejército. La pertenencia de ambos hermanos a la legio VII nos pone también en contacto con los patrones de reclutamiento de esta unidad, constatando que, pese a su creciente vinculación con Hispania, de donde procedían la mayoría de sus miembros, aún seguía reclutando soldados de Italia durante el siglo II d.C. ${ }^{82}$

Algo más tardío es el testimonio del quinto de los militares itálicos documentados en este apartado. Se trata de C. M(- -) Zosimus, beneficiarius de la VII Gemina,

74 AE 1968, 206: M(arcus) Tavonius / M(arci) f(ilius) Rom(ilia) Firmus / dom(o) Ateste mil(es) / leg(ionis) VI Victr(icis) |(centuria) P(ubli) Sexti / an(norum) XXX aer(orum) XI h(ic) s(itus) e(st) / s(it) t(ibi) t(erra) l(evis). Kubistschek 1972 [1889], 107.

76 Le Roux 1982, 269; Hernández Guerra 2007, 46; Gómez-Pantoja - Castillo Sanz 2014, 511 , nº 4 (posterior al año 40 d.C.).

77 Sobre el uso de esta expresión para indicar los años de servicio: Gómez-Pantoja - Castillo Sanz 2014, $507-518$.

78 Le Roux 1982, 269.

79 En Hidalgo et alii 2019, en adelante citado como NEFAE. Aquí NEFAE 85: D(is) M(anibus) s(acrum) L(ucio) Aver/cio L(uci) f(ilio) ex Ital(ia) Quir(ina) Pe/lt(u)ino Celeri vet(e)ra/no l(egionis) VII G(eminae) Fel(icis) L(ucius) A\{v\}verci/us Maxsimus(!) convet(e)/ranus fratri pio / h(ic) sit(us) s(it) t(ibi) $t$ (erra) $<l=T>$ (evis).

80 Kubistschek 1972 [1889], 60.

81 Salomies 1987, 378-388. Asimismo, el comentario de esta inscripción en NEFAE 85.

82 Al respecto véase Palao Vicente 1998, 145-166, y 2006, 109-183, con datos resumidos en las tablas II-V. 
unidad en la que sirvió durante dos décadas. ${ }^{83} \mathrm{Su}$ muerte, acontecida cuando contaba con algo más de 37 años, tuvo lugar entre finales del siglo II d.C. y comienzos del III d.C. Más en concreto, la presencia del epíteto Pia en la nomenclatura de la legio VII conforma un terminus post quem que permite fechar este epígrafe con posterioridad al año 197, momento en que Septimio Severo otorgó este apelativo a la unidad, que a partir de entonces aparece referida en las inscripciones con el título de Gemina Pia Felix. ${ }^{84}$ Esta circunstancia permite situar el reclutamiento de Zosimus a mediados de la segunda centuria, cuando contaba con apenas 17 años. La ausencia de cualquier referencia a la honesta missio sugiere que su fallecimiento habría tenido lugar mientras se encontraba en activo, quizás sirviendo en el officium del gobernador de Lusitania. ${ }^{85}$ Fue homenajeado por su esposa, Iunia Vera, encargada de levantar su monumento funerario. En él se recoge la origo de este beneficiarius, que aparece indicada mediante la expresión natione Italo.

En último término debemos señalar las inscripciones de Iulia Restituta y de $M$. Aurelius Fhilo, que no presentan naturaleza militar. La primera fue enterrada junto a su esposo, C. Duccius Phoebus (véase infra $\S 3.4$ ), de probable origen galo, en la segunda mitad del siglo I d.C. De ella sabemos que era originaria de Roma (domo Roma) y que falleció a la avanzada edad de 83 años. ${ }^{86}$ Por su parte, M. Aurelius Fhilo está documentado en una inscripción de época posterior. Se trata de un titulus pictus realizado sobre estuco rojo y enmarcado por una tabula ansata que estuvo situado en la entrada norte del anfiteatro de Mérida. ${ }^{87}$ En él se conmemora el cumplimiento de un voto a Dea Caelestis Nemesis realizado por parte de este personaje oriundo de Roma. ${ }^{88}$ Tanto su onomástica, en la que destaca el gentilicio Aurelius, propio de los últimos Antoninos y también de los Severos, como el culto a Némesis, permiten situar la inscripción entre finales del siglo II y comienzos del III d.C. ${ }^{89}$ Existen divergencias sobre la posición social de $M$. Aurelius, que ha sido considerado un ciudadano romano de origen itálico, ${ }^{90}$ un gladiador, ${ }^{91}$ un legionario veterano, ${ }^{92}$ un liberto imperial, ${ }^{93}$ e incluso un peregrinus beneficiado por los efectos de la Constitutio Antoniniana. ${ }^{94}$ De igual modo, son también diversas las propuestas realizadas sobre su cognomen, único punto de la inscripción que presenta problemas

83 AE 1983, 487: D(is) M(anibus) s(acrum) / G(aio) M(- - -) Zosimo b(ene)f(iciario) leg(ionis) / VII Gem(inae) P(iae) F(elicis) natione / Italo stipe(n)dior $<u m>/ X X q$ (ui) vixit ann(i)s / XXXVII mensibus VII / diebus XXXXVIIII Iunia / Vera coniug(i) benignissi/mo [.] urcinio posuit / h(ic) [s(itus)] e(st) s(it) t(ibi) t(erra) l(evis). Sobre esta inscripción, Alföldy 1991, 168-172 y Le Roux 1992, 264-265, donde ambos autores señalan los errores ortográficos y problemas de interpretación que presenta el texto.

84 Le Roux 2000, 392; Rodríguez González 2001, 250-251; Palao Vicente 2006, 87-88.

85 Alföldy 1991, 172; Le Roux 1992, 265; Palao Vicente 2006, 152156 y 290.

86 AE 1994, 841: C(aius) Duccius Phoebus / ann(orum) LXXX / huic colonia Emeritensis / locum sepulturae impensam / funeris decrevit / Iulia Restituta uxor / domo Roma annorum LXXXIII / h(ic) s(iti) s(unt) s(it) v(obis) t(erra) l(evis).

87 AE 1961, 48: Deae Invictae / Caelesti Nemesi / M(arcus) Aurelius Fhilo (!) / Roma v(otum) s(olvit) a(nimo) l(ibens) / sacra v(ota) s(olvit) m(erito).

88 La asociación entre ambas divinidades se observa también en el anfiteatro de Italica (CILA 3, 348). Al respecto, Gómez-Pantoja 2009, 181, donde se incluye la correspondiente bibliografía.

89 García y Bellido 1959, 128; Haley 1986, 139.

90 García Iglesias 1972, 84.

91 Ramírez Sádaba 2008, 83.

92 García y Bellido 1957, 473; 1960, 143; Ramírez Sádaba 1993, 391.

93 García y Bellido 1957, 473; 1960, 143.

94 García y Bellido 1967, 90. 
de lectura. Inicialmente, A. García y Bellido pensó que estaría incompleto y sólo restituyó su parte inicial, en la que leía Fili[- - -.${ }^{95}$ Más tarde fueron planteadas otras propuestas, como las enunciadas por J. L. Ramírez Sádaba, que desarrolló el cognomen como Feli(c)io, ${ }^{96}$ o la de $\mathrm{M}^{\mathrm{a}} \mathrm{C}$. Marín, que se decantaba por Feles o Felix.$^{97}$ Por su parte, J. Gómez-Pantoja considera que el cognomen está completo y lo restituye como Fhil[o].98

\begin{tabular}{|c|c|c|c|c|c|c|}
\hline Onomástica & Cron. & Origo & Tribu & Status & $\begin{array}{c}\text { Función } \\
\text { social }\end{array}$ & Referencia \\
\hline $\begin{array}{c}\text { Marcus } \\
\text { Aurelius } \\
\text { Fhilo }\end{array}$ & $\begin{array}{l}\text { Transición ss.II } \\
\text { al III d.C. }\end{array}$ & Roma & & $\begin{array}{c}\text { Civis } \\
\text { Romanus }\end{array}$ & & $A E 1961,48$ \\
\hline $\begin{array}{l}\text { Lucius } \\
\text { Avercius } \\
\text { Celer }\end{array}$ & Siglo II d.C. & Peltuinum & Quirina & $\begin{array}{c}\text { Civis } \\
\text { Romanus }\end{array}$ & $\begin{array}{c}\text { Veteranus } \\
\text { legionis VII } \\
\text { Geminae }\end{array}$ & NEFAE 85 \\
\hline $\begin{array}{c}\text { Lucius } \\
\text { Avercius } \\
\text { Maxsimus } \\
\end{array}$ & Siglo II d.C. & Peltuinum & Quirina & $\begin{array}{c}\text { Civis } \\
\text { Romanus }\end{array}$ & $\begin{array}{c}\text { Veteranus } \\
\text { legionis VII } \\
\text { Geminae }\end{array}$ & NEFAE 85 \\
\hline $\begin{array}{c}\text { Marcus } \\
\text { Furius } \\
\text { Flo[rus?] }\end{array}$ & $\begin{array}{c}\text { Siglo I d.C. } \\
\text { Años 69-70 d.C. }\end{array}$ & $\begin{array}{l}\text { Natione } \\
\text { Italicus }\end{array}$ & & $\begin{array}{c}\text { Civis } \\
\text { Romanus }\end{array}$ & $\begin{array}{c}\text { ¿Miles } \\
\text { legionis } \\
\text { I Adiutricis? }\end{array}$ & $\begin{array}{c}A E 1980, \\
548\end{array}$ \\
\hline $\begin{array}{c}\text { Iulia } \\
\text { Restituta }\end{array}$ & $\begin{array}{c}\text { Segunda } \\
\text { mitad s. I d.C. }\end{array}$ & $\begin{array}{l}\text { Domo } \\
\text { Roma }\end{array}$ & & $\begin{array}{c}\text { Civis } \\
\text { Romana }\end{array}$ & & $\begin{array}{c}\text { AE 1994, } \\
841 \\
\end{array}$ \\
\hline $\begin{array}{c}\text { Caius } \\
\text { M(- - -) } \\
\text { Zosimus }\end{array}$ & $\begin{array}{c}\text { Transición } \\
\text { ss. II al III d.C. }\end{array}$ & $\begin{array}{l}\text { Natione } \\
\text { Italo }\end{array}$ & & $\begin{array}{c}\text { Civis } \\
\text { Romanus }\end{array}$ & $\begin{array}{c}\text { Beneficiarius } \\
\text { legionis VII } \\
\text { Geminae } \\
\text { Piae Fidelis } \\
\end{array}$ & $\begin{array}{c}A E 1983, \\
487\end{array}$ \\
\hline $\begin{array}{c}\text { Marcus } \\
\text { Tavonius } \\
\text { Firmus }\end{array}$ & $\begin{array}{c}\text { Siglo I. } \\
\text { Posterior al } \\
\text { año } 40 \text { d.C. }\end{array}$ & $\begin{array}{l}\text { Domo } \\
\text { Ateste }\end{array}$ & Romilia & $\begin{array}{c}\text { Civis } \\
\text { Romanus }\end{array}$ & $\begin{array}{c}\text { Miles } \\
\text { legionis } \\
\text { VI Victricis }\end{array}$ & $\begin{array}{c}A E 1968, \\
206\end{array}$ \\
\hline
\end{tabular}

Tabla 3. Inmigrantes de origen itálico documentados en Augusta Emerita

\subsection{Africanos}

Los africanos son el segundo grupo de población foránea más numeroso registrado en el periodo posterior a la fundación de Augusta Emerita. En concreto, constatamos la presencia en la ciudad de seis individuos procedentes de este ámbito geográfico, que abarcaría las provincias de Mauretania Tingitana, Mauretania Caesariensis, Africa Proconsularis y Cyrenaica. Cronológicamente, sus inscripciones remiten a dos periodos muy concretos, el siglo I d.C., para el que contamos con dos epígrafes, y el periodo comprendido desde mediados del siglo II en adelante, etapa en la que se concentran los cuatro restantes.

\footnotetext{
95 García y Bellido 1957, 473; 1959, 128.

96 Ramírez Sádaba 1995, 291, aunque posteriormente $(2008,83)$ se decanta por leer Philo. La lectura Feli(c)io es aceptada también por Ceballos Hornero 2004, 546.

97 Marín Ceballos 1993, 841.

98 Gómez-Pantoja 2009, 180-181.
} 
A la primera centuria pertenecen las inscripciones de Servilia Secunda ${ }^{99}$ oriunda de Tingis (Mauretania Tingitana) y fallecida en Augusta Emerita a los 67 años, y de la liberta Quinta Caecilia, ${ }^{100}$ a quien podemos suponer natural de Mauretania guiándonos por el apelativo Mauriola que figura en la tercera línea y que muy posiblemente fue el antiguo nombre de esclava de esta mujer. ${ }^{101}$ Dicho término, que conforma un hápax en la epigrafía latina, ${ }^{102}$ podría ser un derivado del cognomen Maurus, clasificado por I. Kajanto entre los cognomina de origen étnico-geográfico $y$ del que conocemos varios ejemplos en Hispania. ${ }^{103}$ Presenta, asimismo, la peculiaridad de finalizar con el sufijo -iola, una forma habitual de convertirlo en un diminutivo, posiblemente de tipo cariñoso. ${ }^{104}$ Esta inscripción resulta igualmente interesante desde un punto de vista social, puesto que constata la existencia de un matrimonio entre dos libertos, la mencionada Quinta Caecilia y C. Iulius Felix, cuyas estructuras onomásticas permiten suponer que habrían pertenecido a casas diferentes durante su etapa servil. ${ }^{105}$ Ambos fueron homenajeados por su hijo, $C$. Iulius Modestus, que posteriormente fue enterrado junto a ellos. ${ }^{106}$ Esta circunstancia condiciona la cronología de la inscripción, ya que la paleografía de las tres primeras líneas parece remitir a época tiberiana, mientras que las características de la cuarta, donde figura el nombre del hijo fallecido, se sitúan en el reinado de Claudio. ${ }^{107}$

Las restantes inscripciones relativas a inmigrantes africanos en Augusta Emerita se fechan a partir de mediados del siglo II d.C. Durante este periodo la principal causa de movilidad entre los Africani registrados en la capital lusitana fue el servicio en el ejército. Así podemos observarlo en los casos del veteranus L. Licinius Setianus ${ }^{108}$ y del beneficiarius Geminius Gargilianus. El primero de ellos fue identificado por J. M. Roldán Hervás como un ciudadano emeritense, ${ }^{109}$ una propuesta que debe descartarse por la pertenencia de Licinius Setianus a la tribu Quirina, que no es propia de los habitantes de Mérida, y por señalar expresamente su procedencia como Cirtensi. Esta origo lo vincula con la ciudad norteafricana de Cirta (actual Constantina, Argelia), como observó P. Le Roux, cuya consideración han seguido

99 ERAE 196: D(is) M(anibus) s(acrum) / Servilia G(ai!) f(ilia) / Secunda Ting(itana) / ann(orum) LXVII / h(ic) s(ita) e(st) s(it) t(ibi) t(erra) l(evis) / Helvia Rusticilla / d(e) (!) f(aciendum) c(uravit).

100 AE 2000, 692: C(aius) Iulius C(ai) l(ibertus) Felix / Quinta Caecilia / (mulieris) l(iberta) Mauriola s(it) t(ibi) t(erra) l(evis) / C(aius) Iulius Modestus ann(orum) XXVII.

101 García y Bellido 1959, 147; Bendala Galán 1972, 237 y 238; Lefebvre 2006, 114.

102 Solin - Salomies 1988, 360.

103 Kajanto 1982, 206; Abascal Palazón 1994, 420-421; Navarro Caballero - Ramírez Sádaba 2003, 233-234. Sobre la posibilidad de que este cognomen y sus derivados indiquen la existencia o no de una movilidad geográfica, Lefebvre 2006, 111-115.

104 García y Bellido 1959, 147; Bendala Galán 1972, 237-238. Cabe también la posibilidad de que el apelativo Mauriola no derivase necesariamente del étnico Maurus, sino de otro cognomen de raíz similar. Sobre la formación de los cognomina finalizados en -(i)olus véanse las consideraciones realizadas por Solin 2014, 384385 .

105 Edmondson 2000, 299; Hernández Guerra 2013, 59.

106 Para Mangas 1971, 324, se trataría del patrono de este matrimonio de libertos, opinión que ha sido rechazada por Bendala 1972, 238; Edmondson 2000, 299, y Hernández Guerra 2013, 59, a partir de una lectura actualizada de la inscripción.

107 Bendala Galán 1972, 237; Edmondson 2000, 299.

108 AE 1911, 91: D(is) M(anibus) s(acrum) / Licinio Setiano / veteran(o) Quirin(a tribu) / Cirtensi ann(orum) LXVIII / [Li]cinia Settiana / [e]t Licinius L(uci) f(ilius) Lepidin[us] / patri piissimo faci/endum curaverunt / h(ic) s(itus) e(st) s(it) t(ibi) t(erra) l(evis).

109 Roldán Hervás 1974, 308-309, nº 588. 
todos los autores posteriores. ${ }^{110}$ Por tanto, Setianus procedería de la zona de Numidia, desde donde se habría trasladado a Hispania como consecuencia de su pertenencia al ejército. ${ }^{111}$ Allí falleció a los 68 años en una fecha que oscila entre finales del siglo II y comienzos del III d.C., circunstancia que permite situar su reclutamiento en la primera mitad o a mediados de la segunda centuria. ${ }^{12}$ En Mérida recibió sepultura y fue homenajeado por sus hijos, Licinia Settiana y Licinius Lepidinus. Ambos son un buen reflejo de la reintegración a la vida civil de este veterano norteafricano que habría servido probablemente en la legio VII Gemina. ${ }^{113}$

En el mismo horizonte cronológico se sitúa la inscripción que Geminius Gargilianus levantó en memoria de su esposa Minicia Paterna, fallecida en Augusta Emerita con 35 años. ${ }^{114}$ La estela, que habría estado ubicada probablemente en una construcción funeraria, incluye un retrato de cierta calidad, un hecho que reflejaría la buena posición social de Gargilianus. ${ }^{115}$ Ésta habría sido alcanzada gracias, posiblemente, a sus años de servicio como beneficiarius consularis en la VII Gemina. Dentro de una legión los beneficiarii formaban parte de los llamados principales, un grupo de soldados que estaban exentos de realizar los munera y cuyo salario solía ser superior al de los simples milites. El disfrute de estos privilegios venía determinado por la realización de tareas especializadas, muchas de ellas de carácter administrativo. ${ }^{116}$ Esta circunstancia permitiría relacionar la presencia de Gargilianus en Augusta Emerita con un posible servicio en el officium del gobernador. ${ }^{117}$ Su situación sería similar a la de Caius M(- - -) Zosimus, un itálico que actuó también como beneficiarius en el officium provincial de Lusitania durante el mismo periodo. ${ }^{118}$

La inscripción de Geminius Gargilianus no recoge su origo, por lo que su procedencia debe inferirse a partir de su onomástica, cuyos elementos parecen remitir al norte de África. ${ }^{119}$ En concreto, el nomen Geminius resulta frecuente en el Africa Proconsularis. ${ }^{120}$ Fuera de ella su volumen se reduce notablemente, como podemos observar en Hispania, donde los casos conocidos apenas superan la veintena. ${ }^{121}$ De ellos, cuatro proceden de territorios pertenecientes a la antigua Lusitania. ${ }^{122}$ En relación al cognomen Gargilianus conviene reseñar que cuatro de las seis personas portadoras del mismo registradas por I. Kajanto procedían del norte de

110 Le Roux 1982, 213, n 148; Haley 1986, 163; Palao Vicente 1998, 150; 2006, 175; Edmondson 2010, 246, $\mathrm{n}^{\circ}$ 11 .

111 No obstante, Le Roux 1982, 213, nº 148, afirmaba que su retirada en Mérida no tenía por qué asociarse automáticamente con un servicio militar en dicha ciudad.

112 Le Roux 1982, 213, nº 148; Palao Vicente 2006, 175; Edmondson 2010, 246, nº 11.

113 Le Roux 1982, 213, n 148; Haley 1986, 163; Palao Vicente 1998, 150; 2006, 175; Edmondson 2010, 246, n 11.

114 AE 1976, 275: Miniciae Paternae ann(orum) XXXV / coniugi dulcissimae et castissimae / Geminius Gargilianus mil(es) leg(ionis) VII G(eminae) b(ene)f(iciarius).

115 Palao Vicente 2006, 376.

116 Palao Vicente 2006, 133 y 139. Sobre los beneficiarii de la VII Gemina, Palao Vicente 2006, 147-158.

117 Le Roux 1982, 235; Edmondson 2001a, 82; 2001b, 147; Palao Vicente 2006, 152, 290 y 340.

118 AE 1983, 487.

119 Le Roux 1982, 235; Haley 1986, 166, no 3; Palao Vicente 1998, 152; 2006, 156 y 179; Edmondson 2001a, 82; 2001b, 146.

120 Cf. los índices de CIL VIII.

121 Abascal Palazón 1994, 146.

122 Navarro Caballero - Ramírez Sádaba 2003, 185. 
África. ${ }^{123}$ De igual modo, es importante tener en cuenta que este cognomen conforma un derivado del gentilicio Gargilius, bastante frecuente en el área norteafricana, circunstancia que reforzaría la propuesta de un origen africano para este beneficiarius de la legio VII. ${ }^{124}$

Finalmente, contamos con la presencia en Augusta Emerita de un tercer militar del que sólo conocemos la parte final de su cognomen, [- - - Jilis. ${ }^{125} \mathrm{Su}$ inscripción ha sido datada entre los años 180 y 230 d.C., aunque, por desgracia, no se ha conservado completa, ya que sólo contamos con cinco fragmentos de su parte derecha, más un sexto trozo aislado. A pesar de estas pérdidas los datos conservados certifican la presencia en el texto de dos personas, el referido [- - -Jilis, un veteranus del ejército, y su esposa, de nombre también incompleto. Uno de los datos más interesantes que ha llegado hasta nosotros es la origo de este militar, Bagai(ensis), que posiblemente haga referencia a la ciudad de Bagai (Ksar Baghai, Argelia), población que podemos identificar con una comunidad ubicada a poca distancia de Mascula, en Numidia meridional (Africa Proconsularis). ${ }^{126}$ [- - - Jilis desarrolló su servicio militar en un ala miliaria destinada en la Mauretania Caesariensis, probablemente una unidad de carácter auxiliar acantonada en esta provincia. Este cuerpo no tuvo ninguna relación directa con la Península Ibérica, por lo que resulta complicado vincular la presencia de [- - Jilis en Augusta Emerita con alguna actividad militar o administrativa. Por ello, es probable que su establecimiento en la capital de Lusitania hubiese tenido lugar tras su desmovilización. Se trataría, por tanto, de un veterano del ejército del norte de África que tras su retiro habría optado por asentarse en Mérida, donde falleció a los 61 años. Es posible que allí hubiese contraído matrimonio y creado una familia, aunque no conocemos prácticamente nada sobre la onomástica o el origen de su esposa debido a las roturas de la inscripción, cuya parte final está ocupada por un pequeño carmen. ${ }^{127}$

En la primera mitad del siglo III d.C. se encuadra también la última inscripción de este apartado, cuyo protagonista, en este caso, nada tiene que ver con el ejército. El epígrafe en cuestión recoge el epitafio de Antonius Saturninus, fallecido a los 71 años, y de su esposa, Ulpia Iuniana, enterrada junto a él. ${ }^{128}$ Fue grabado en la base de un monumento funerario realizado en mármol blanco y decorado con los retratos de la pareja difunta. ${ }^{129}$ En lo que a este trabajo respecta interesa constatar el origen foráneo de Antonius Saturninus, que se describe como Madaurensis, término que aludiría a los habitantes de la ciudad de Madauros, ubicada en la región de Numidia. ${ }^{130} \mathrm{Su}$ origen norteafricano se vería igualmente reforzado por su

123 Kajanto 1982, 147. En Hispania la presencia de este cognomen se limita a este caso: Abascal Palazón 1994, 378; Navarro Caballero - Ramírez Sádaba 2003, 184.

124 Cf. los índices de $C I L$ VIII.

125 AE 2009, 519: [D(is)] M(anibus) s(acrum) / [- - -]ilis vet(eranus) al(a)e |(miliariae) orig(ine) / [- - - castel]l(o?) Bagai(ensium?) an(norum) LXI / [- - -] dom(us) aeterna / [- - - ux]ori meae Alli/[ae(?) - - -] item [v(ixit)] a(nnos) LV / [- - - memo]riae [- - ]pon/[- - -] titulum feci / ut genus innotu[m i]nnotescere / possit nam tu qui le [gis nunc dica]s (e)st in eo / [c] um tibi datum [erit - - - ven]ies. Para un estudio de esta inscripción, Le Roux - Ramírez Sádaba 2009, 297-306.

126 Le Roux - Ramírez Sádaba 2009, 299.

127 Al respecto, Ramírez Sádaba 2009, 279-289; Carande Herrero 2011, 235-244.

128 ERAE 159: [D(is)] M(anibus) s(acrum) / Ulpia Iuniana et Antonius Saturninus / Madaurensis ann(orum) LXXI me vivo f(aciendum) c(uravit) si qui de meis / super eos annos auserit post obitum meum tamquam / - - - - - .

129 Sobre las características de estos retratos, Nogales Basarrate 1997, 124-126; Edmondson 2001b, 158-162.

130 García y Bellido 1959, 146; Haley 1986, 163; Edmondson 2001b, 161. 
cognomen, un teofórico derivado del culto a Saturno muy abundante en esta zona del Imperio. ${ }^{131}$

\begin{tabular}{|c|c|c|c|c|c|c|}
\hline Onomástica & Cron. & Origo & Tribu & Status & $\begin{array}{c}\text { Función } \\
\text { Social }\end{array}$ & Referencia \\
\hline $\begin{array}{c}\text { Quinta } \\
\text { Caecilia } \\
\text { Mauriola }\end{array}$ & $\begin{array}{l}\text { Siglo I d.C. } \\
\text { Reinado de } \\
\text { Tiberio }\end{array}$ & $\begin{array}{c}\text { Probablemente } \\
\text { Mauretania }\end{array}$ & & Liberta & & $\begin{array}{l}A E 2000, \\
\quad 692\end{array}$ \\
\hline $\begin{array}{c}\text { Geminius } \\
\text { Gargilianus }\end{array}$ & $\begin{array}{l}\text { Primera mitad } \\
\text { s. III d.C. }\end{array}$ & $\begin{array}{c}\text { Probablemente } \\
\text { Africanus }\end{array}$ & & $\begin{array}{c}\text { Civis } \\
\text { Romanus }\end{array}$ & $\begin{array}{c}\text { Miles et } \\
\text { beneficiarius } \\
\text { legionis VII } \\
\text { Geminae }\end{array}$ & $\begin{array}{c}A E 1976, \\
275\end{array}$ \\
\hline $\begin{array}{c}\text { Antonius } \\
\text { Saturninus }\end{array}$ & $\begin{array}{l}\text { Primera mitad } \\
\text { s. III d.C. }\end{array}$ & Madaurensis & & $\begin{array}{c}\text { Civis } \\
\text { Romanus }\end{array}$ & & ERAE 159 \\
\hline $\begin{array}{l}\text { Lucius } \\
\text { Licinius } \\
\text { Setianus }\end{array}$ & $\begin{array}{l}\text { Transición ss. } \\
\text { II al III d.C. }\end{array}$ & Cirtensis & Quirina & $\begin{array}{c}\text { Civis } \\
\text { Romanus }\end{array}$ & $\begin{array}{c}\text { Veteranus } \\
\text { ¿Legionis VII } \\
\text { Geminae? }\end{array}$ & $A E 1911,91$ \\
\hline $\begin{array}{l}\text { Servilia } \\
\text { Secunda }\end{array}$ & $\begin{array}{l}\text { Finales } \\
\text { s. I d.C. }\end{array}$ & Tingitana & & $\begin{array}{c}\text { Civis } \\
\text { Romana }\end{array}$ & & ERAE 196 \\
\hline [- - -Jilis & $\begin{array}{l}\text { Entre los años } \\
180 \text { y } 230 \text { d.C. }\end{array}$ & Bagaiensis & & $\begin{array}{c}\text { Civis } \\
\text { Romanus }\end{array}$ & $\begin{array}{c}\text { Veteranus Alae } \\
\text { Miliariae }\end{array}$ & $\begin{array}{c}A E 2009, \\
519\end{array}$ \\
\hline
\end{tabular}

Tabla 4. Inmigrantes de origen africano documentados en Augusta Emerita

\subsection{Orientales}

En tercer lugar encontramos a los inmigrantes de origen oriental, cuyo volumen alcanza también los seis casos. Este sector del Mediterráneo conformaba un amplio espacio geográfico caracterizado por su enorme diversidad lingüística y cultural. Para elaborar este apartado hemos seleccionado únicamente las inscripciones donde sus protagonistas hicieron constar la origo, aunque a este grupo hemos añadido también un epígrafe cuyo texto, escrito en griego y en latín, podría constituir un indicador del origen de los dedicantes de la inscripción. Por el contrario, hemos excluido de nuestro trabajo aquellos epígrafes en los que únicamente contamos con la onomástica como elemento indicador de una posible movilidad, ya que tanto la onomástica griega, muy difundida por todo el Imperio, como los nombres de origen semita, no permiten asegurar en todos los casos que sus portadores procedan de esta zona del Mediterráneo. ${ }^{132}$

El empleo de estos criterios ha limitado a cinco las inscripciones incluidas en este apartado. Tres de ellas aluden a individuos procedentes de Asia Menor. La más antigua es el epitafio de Demetrius, que ha sido datado en la primera mitad del siglo I d.C. ${ }^{133}$ La inscripción, realizada sobre una placa de mármol blanco, está compuesta por un texto breve y un formulario bastante simple. Fue dedicada por un personaje llamado Vicarius, que se identifica como liberto del fallecido. En ella destaca particularmente el término Azzanites, que podría interpretarse de tres formas

131 Kajanto 1982, 213.

132 Haley 1986, 156-158; Beltrán Fortes 2013, 185-188 y 193-195.

133 NEFAE 86: Demetrius / Azzanites / h(ic) s(itus) e(st) / Vicarius / lib(ertus) pa[t]rono / <et> suis fecit. 
diferentes: como el cognomen de Demetrius; como su profesión, entendiendo que este vocablo podría estar aludiendo a la denominación que recibían algunos de los ayudantes que oficiaban en las sinagogas emeritenses; y, finalmente, como origo, hipótesis esta última que los editores de la pieza consideran como la más probable. ${ }^{134}$ De ser así, el término Azzanites, quizás una variante mal escrita del correcto Aizanites, podría estar aludiendo a la ciudad frigia de Aizanoi (actual Çavdarhisar, Turquía), posible lugar de origen de Demetrius. Desde allí se habría desplazado hasta Augusta Emerita por causas que desconocemos. No obstante, su onomástica simple y de origen griego permite identificarlo como un posible liberto, ${ }^{135}$ por lo que quizás su llegada a Mérida hubiese estado relacionada con el traslado de su patrono o de su amo, si es que este se produjo cuando aún era esclavo.

Un poco posterior es la inscripción de Q. Octaus Sperchius, que también era natural de Frigia (Phryx). ${ }^{136}$ Su epitafio fue datado inicialmente por J. L. de la Barrera en la segunda mitad del siglo II d.C., ${ }^{137}$ aunque J. Gómez-Pantoja ha considerado más apropiado situarlo en el siglo I d.C. atendiendo, entre otros elementos, a la simplicidad del formulario. ${ }^{138}$ En él se indica que Sperchius fue un gladiator del tipo secutor, una especialidad desconocida en Hispania hasta el momento en que fue descubierto este epígrafe, que, de hecho, conforma el único testimonio de la misma documentado en la Península Ibérica. ${ }^{139}$ Tanto su temprana muerte, acaecida a los 24 años, como la ausencia de cualquier referencia a las victorias obtenidas, indicarían que este luchador tuvo una carrera corta y poco exitosa, ${ }^{140}$ siendo sugerente la idea de que hubiera fallecido durante el transcurso de un combate en el anfiteatro emeritense. ${ }^{141}$ Su epitafio fue erigido por Acilia Aurora, probablemente su compañera o esposa, cuyo duo nomina indicaría su condición de ingenua ${ }^{142}$ Esta circunstancia, unida a la onomástica con tria nomina de Q. Octaus Sperchius, que rompe con el esquema onomástico generalmente simple que encontramos en el mundo gladiatorio, hace difícil suponer que este secutor fuese un esclavo, siendo quizás más factible considerarlo un auctoratus. ${ }^{143}$

También procedía de Asia Menor, en este caso de Nicomedia, la posible liberta Iulia Glyconis. ${ }^{144}$ Desde allí se habría desplazado hasta Augusta Emerita, donde falleció a los 45 años durante el siglo II d.C. Tras su muerte fue homenajeada por sus hijos, L. Munatius Asclepiades y M. Lucanius Avitus, cuya onomástica conforma uno de los elementos más curiosos de esta inscripción, ya que ambos presentan distintos gentilicios y cognomina de diferente origen. En concreto, Asclepiades porta

134 Al respecto véase el comentario de esta inscripción en NEFAE 86.

135 Delgado Molina 2017, 553. Sobre su onomástica: Solin 1982, 296-300 y 1372.

136 AE 1989, 395: Q(uintus) Octaus Sper/chius Phryx / secutor ann(orum) / XXIIII / h(ic) s(itus) e(st) s(it) t(ibi) t(erra) l(evis) / Acilia Auro[r]a / [f(aciendum) c(uravit)].

137 De la Barrera Antón 1988, 124. Esta cronología es seguida por Ceballos Hornero 2004, 487.

138 Gómez-Pantoja 2009, 109.

139 De la Barrera Antón 1988, 122; Gómez-Pantoja 2009, 108.

140 Gómez-Pantoja 2009, 108.

141 Nogales Basarrate 2000, 88.

142 Ceballos Hornero 2004, 488; Gómez-Pantoja 2009, 108.

143 Ceballos Hornero 2004, 488; Gómez-Pantoja 2009, 108. J. de la Barrera 1988, 122, lo consideró un liberto.

144 AE 1993, 907: D(is) M(anibus) [s(acrum)] / Iul(ia) Glyconis / nat(ione) Nicomedica / ann(norum) XXXXV s(it) t(ibi) t(erra) l(evis) / L(ucius) Munatius As/clepiades et M(arcus) Lu/canius Avit(us) f(ilii) m(atri) p(iissimae) f(ecerunt). 
un cognomen greco-oriental, ${ }^{145}$ mientras que Avitus presenta un cognomen latino, ${ }^{146}$ o quizás indígena, ${ }^{147}$ muy frecuente en Hispania. ${ }^{148}$ Igualmente, la presencia de diferentes gentilicios en la onomástica de dos personajes considerados hermanos resulta compleja. Quizás pudo deberse a que ambos eran hijos de distinto padre, aunque no podemos descartar otras opciones, como que uno de ellos hubiese sido adoptado por otra gens o, incluso, si aceptamos que se trata de una familia de libertos, que hubiesen tenido dueños diferentes. ${ }^{149}$

En cuarto lugar encontramos el caso de Iustinus, natural de Flavia Neapolis, la actual Sichen (Cisjordania, Palestina), que falleció en Augusta Emerita también durante el siglo II d.C. ${ }^{150}$ En la capital lusitana fue homenajeado por su esposa, Sabina, y por sus hijos, Menander y Salvina, quienes costearon su inscripción. Resulta imposible determinar los motivos que llevaron a Iustinus y a su familia a instalarse en un lugar tan alejado de su patria natal. A pesar de ello, A. García y Bellido, tomando como base la localización de Flavia Neapolis en la costa palestina, sugirió la posibilidad de que Iustinus fuese un judío llegado a la Península Ibérica por la diáspora generada tras la destrucción de Jerusalén en época de Adriano, una apreciación con la que coincidió parcialmente L. García Iglesias. ${ }^{151}$ Ambos autores señalaron, no obstante, que el único elemento que permitía plantear esta hipótesis era la ciudad de origen de Iustinus, ya que tanto su onomástica, perfectamente latina, como la de sus hijos, donde podemos observar un nombre griego en el caso del varón, Menander, y otro latino en el caso de la mujer, Salvina, no nos aporta ninguna información en este sentido. Quizás por ello, H. Solin y E. W. Haley prefirieron atribuir a Iustinus un origen sirio. ${ }^{152}$

Finalmente, debemos señalar el posible origen oriental de Gaiena y Sosthenes, padres del joven Iulianus, a quien dedicaron un epitafio bilingüe tras su prematura muerte con apenas siete meses. ${ }^{153}$ Se trata de una estela de mármol blanco de notable calidad en cuya parte superior podemos ver, dispuesta en el interior de una hornacina, la figura de un niño alado abrazando un racimo de uvas, una iconografía que podría estar reflejando la asimilación del fallecido con una divinidad, en este caso el dios Dioniso, ya que los cupidos son bastante frecuentes en monumentos funerarios romanos dedicados a niños. ${ }^{154}$ En ella fue grabado un epigrama formado por dos dísticos griegos y uno latino en los que el propio difunto cuenta en primera

${ }_{145}$ Solin 1982,356.

146 Kajanto 1982, 304.

147 Albertos Firmat 1996, 45.

148 Abascal Palazón 1994, 294-296. En concreto sobre Lusitania, Navarro Caballero - Ramírez Sádaba 2003, 107110. Sobre el carácter regional del cognomen Avitus, Haley 1986, 92.

149 Saquete Chamizo - Márquez Pérez 1993, 61. Ambos autores se mostraron prudentes sobre el status social de estos personajes. Pese a ello, tanto la madre como los hijos han sido incluidos por Hernández Guerra en su obra sobre los libertos en Hispania (Hernández Guerra 2016, 80, nº 257, 88, $\mathrm{n}^{\circ} 349$ y 150, $\mathrm{n}^{\circ} 1161$ ).

150 CIL II 515: Iustinus Menandri filius / Flavius Neapolitanus anno(rum) / XLVI h(ic) s(itus) e(st) s(it) t(ibi) t(erra) l(evis) Sabina marit(o) / optimo et merentissimo et / Menander filius cum seroribus(!) / suis Rece[pt] a et Salvina / patri piissimo [- - -] / p(onendum) [c(uravit)].

151 García y Bellido 1959, 143; García Iglesias 1973, 341-342.

152 Solin 1983, 587-589; Haley 1986, 157.

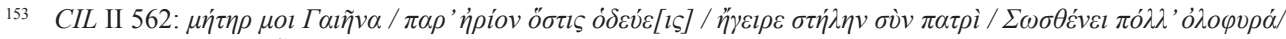

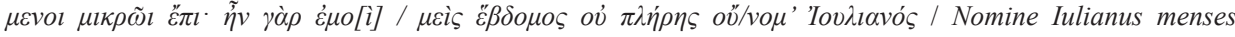
exc[e]/dere septem haut licitum mul/tum flevit uterque parens.

154 Edmondson 2001, 141 
persona la tristeza y el dolor experimentados por sus padres ante su temprana muerte. El carácter bilingüe de la inscripción tiene su correspondiente proyección en la onomástica de los personajes mencionados en el texto, donde encontramos un nombre latino, Iulianus, y dos de clara ascendencia griega, Gaiena y Sosthenes. ${ }^{155}$ Este hecho, junto a la simpleza de sus estructuras onomásticas, permitiría plantear la posibilidad de que los progenitores del pequeño difunto fuesen simplemente dos esclavos que pusieron a su hijo el nombre de su dueño. Sin embargo, como han subrayado varios autores, tanto la calidad y riqueza decorativa de la estela funeraria, que sugieren una buena situación económica, como el empleo de una composición métrica en el epitafio, que nos estaría indicando la posesión de un cierto nivel cultural, son elementos que difícilmente podemos asociar con el mundo de la servidumbre. Por ello, es más probable que nos encontremos ante dos inmigrantes de origen griego, quizás comerciantes, que habrían llegado a la colonia emeritense entre la segunda mitad del siglo II y comienzos del III d.C. movidos por sus intereses económicos. ${ }^{156}$ Es posible que allí hubiera nacido su hijo, al que otorgaron un nombre latino con el objetivo de facilitar su integración en la nueva ciudad, una adaptación al ambiente romano que también podría observarse en la traducción latina del texto y en la iconografía que decora la cabecera de la estela. ${ }^{157}$ Ello no habría implicado, en cualquier caso, el olvido del origen griego de la familia, que se reflejaría en el bilingüismo del epitafio del joven Iulianus.

\begin{tabular}{|c|c|c|c|c|c|}
\hline Onomástica & Cron. & Origo & Status & $\begin{array}{c}\text { Función } \\
\text { social }\end{array}$ & Referencia \\
\hline Demetrius & $\begin{array}{c}\text { Primera mitad } \\
\text { s. I d.C. }\end{array}$ & Aizanoi & iLibertus? & NEFAE 86 \\
\hline Gaiena & $\begin{array}{c}\text { Transición } \\
\text { ss. II-III d.C. }\end{array}$ & $\begin{array}{c}\text { Probablemente } \\
\text { griega }\end{array}$ & Peregrina & CIL II 562 \\
\hline $\begin{array}{c}\text { Iulia } \\
\text { Glyconis }\end{array}$ & Siglo II d.C. & $\begin{array}{c}\text { Natione } \\
\text { Nicomedica }\end{array}$ & iLiberta? & AE 1993, 907 \\
\hline $\begin{array}{c}\text { Iustinus } \\
\text { Quintus } \\
\text { Octaus }\end{array}$ & Siglo II d.C. & $\begin{array}{c}\text { Flavius } \\
\text { Neapolitanus }\end{array}$ & Peregrinus & CIL II 515 \\
\hline $\begin{array}{c}\text { Sosthenes } \\
\text { Splo I d.C. }\end{array}$ & $\begin{array}{c}\text { Phryx (Frigia) } \\
\text { ss. II-III d.C. }\end{array}$ & $\begin{array}{c}\text { ingenuus? } \\
\text { griego }\end{array}$ & $\begin{array}{l}\text { Gladiator } \\
\text { (Secutor) }\end{array}$ & AE 1989, 395 \\
\hline
\end{tabular}

Tabla 5. Inmigrantes de origen oriental documentados en Augusta Emerita

\subsection{Galos}

Tampoco es muy numerosa la presencia en la capital lusitana de individuos de origen galo, cuyo volumen se reduce a dos inscripciones datadas en el siglo I d.C. ${ }^{158}$ La más

\footnotetext{
155 Solin 1982, 150. Asimismo, las consideraciones sobre ambos nombres recogidas en De Hoz 2014, 429.

156 Edmondson 2001, 82 y 141; De Hoz 2014, 429; Pardo Anta 2017, 38, 66-67 y 82.

157 Edmondson 2001, 141; De Hoz 2014, 429.

158 Sobre la presencia gala en Hispania, Ortiz Córdoba 2019b, 151-201.
} 
destacada, si nos atenemos a la carrera pública de su protagonista, es el epitafio de $T$. Pompeius Albinus, originario de Vienna (Gallia Narbonensis). ${ }^{159}$ Allí habría iniciado su cursus honorum con el ejercicio del duunvirato, responsabilidad tras la cual desempeñó una milicia ecuestre, el tribunado de la legio VI, quizás en Hispania. Con posterioridad fue designado por su compatriota T. Decidius Domitianus, también originario de la Narbonense, como adiutor procuratoris de Lusitania, provincia en la que falleció durante el ejercicio de su cargo, un acontecimiento que debemos suponer habría sido fortuito y que, según $\mathrm{S}$. Demougin, tuvo lugar entre los años 60 y 64 d.C. ${ }^{160}$ Fue enterrado en la capital lusitana, aunque su memoria también fue honrada en su ciudad natal, donde su hija, Pompeia Sextina, erigió una inscripción, situada probablemente en un cenotafio, en la que hizo constar la trayectoria pública de su padre. ${ }^{161}$ En ambos homenajes destaca la presencia de la tribu Tromentina en la onomástica de T. Pompeius Albinus, ya que ésta no se corresponde con la tribu Voltinia mayoritaria entre los ciudadanos de Vienna. ${ }^{162}$ Es posible, por tanto, que la familia de Albinus no fuese originaria de esta localidad, pudiendo proceder de alguna de las ciudades de Italia o de la costa dálmata donde la tribu Tromentina era mayoritaria. ${ }^{163}$ En consecuencia, estaríamos ante un descendiente de itálicos y en presencia de un doble caso de emigración, ya que en un primer momento la familia de este personaje se habría instalado en Vienna, ciudad donde posiblemente habría nacido T. Pompeius Albinus, quien, a su vez, se habría trasladado a Hispania como consecuencia del desarrollo de su carrera pública. ${ }^{164}$

Algo más incierta resulta la procedencia de C. Duccius Phoebus, fallecido a los 80 años y enterrado junto a su esposa Iulia Restituta, natural de Roma (véase supra $\S 3.1){ }^{165}$ Tras su fallecimiento la colonia emeritense le honró con la concesión de

159 AE 1935, 5: T(itus) Pompeius T(iti) f(ilius) Trom(entina) / Albinus domo Vienna / IIvir tr(ibunus) mil(itum) leg(ionis) VI Victr(icis) / adiutor T(iti) Decidi Domitiani / procuratoris / Caesaris Augusti / h(ic) s(itus) e(st) s(it) t(ibi) t(erra) l(evis).

160 Demougin 1992, 468. Sobre la trayectoria pública de este personaje: Pflaum 1978, 204, nº 2; Demougin 1992 , $467, \mathrm{n}^{\circ} 562$.

161 CIL XII 2327: T(ito) Pompeio T(iti) f(ilio) [Trom(entina)] / Albino / tribuno mil(itum) leg(ionis) [VI] / Victric(is) subpro[c(uratori)] / provinc(iae) Lusitaniae / IIv(iro) i(ure) d(icundo) col(oniae) Iul(iae) Aug(ustae) Flor(entiae) V(iennensium) / Pompeia T(iti) fil(ia) Sextina. La inscripción fue encontrada en Montmélian, donde los restos hallados sugieren la existencia de un vicus o de una villa que quizás hubiese pertenecido a este personaje. En ella los cargos ejercidos por Albinus están ordenados de forma diferente al epígrafe emeritense, ya que el duunvirato aparece en último lugar. Junto a él figuran, además, todos los epítetos oficiales de la colonia Viennensis, una precisión que fue omitida en la inscripción hispana. De igual modo, la pieza francesa se refiere a Albinus como subprocurator provinciae Lusitaniae, empleando de esta manera el título oficial del cargo. Podemos suponer que con ello Pompeia Sextina pretendía realzar el prestigio de su padre y aclarar a sus conciudadanos el lugar donde había ejercido sus funciones. En contraste, Albinus figura en la inscripción emeritense como adiutor procuratoris, es decir, como asistente de T. Decidius Domitianus, a quien debía su nombramiento. Estas diferencias serían consecuencia de los distintos contextos en que fueron erigidas ambas inscripciones y de los diferentes dedicantes encargados de ejecutarlas (Pflaum 1978, 204). En cualquier caso, el orden real en que Albinus ejerció sus cargos sería, a juicio de Demougin 1992, 468, el que aparece dispuesto en la inscripción de Augusta Emerita. Para un estudio más detallado del epígrafe de Montmélian véase Rémy - Ferber 1991, 267-270.

162 Kubistschek 1972 [1889], 212.

163 Kubistschek 1972 [1889], 272.

164 Rémy - Ferber 1991, 269-270; Demougin 1992, 468; Wierschowski 2001, 14. Sobre el posible origen de la familia de Albinus, Wierschowski 2001, 13-14.

165 AE 1994, 841: C(aius) Duccius Phoebus / ann(orum) LXXX / huic colonia Emeritensis / locum sepulturae impensam / funeris decrevit / Iulia Restituta uxor / domo Roma annorum LXXXIII / h(ic) s(iti) s(unt) s(it) v(obis) t(erra) l(evis). 
un espacio para su sepultura y se hizo cargo de los gastos generados por su funeral, un hecho que indicaría la buena posición disfrutada por Phoebus en la ciudad. Su origen foráneo ha sido planteado a partir de su gentilicio, muy extraño y bastante escaso en la epigrafía latina. ${ }^{166}$ No se documenta ni en Roma ni en Italia y los únicos ejemplos que hemos encontrado de él remiten a la Gallia Narbonensis, donde el nomen Duccius aparece documentado en una inscripción de Aquae Sextiae. ${ }^{167}$ De igual modo, conocemos otro ejemplo de este gentilicio en Eboracum (Britannia), donde figura en la onomástica de un signifer de la legio VIIII originario de Vienna, ciudad de la Gallia Narbonensis. ${ }^{168}$ En la Península Ibérica este nomen se conoce únicamente en esta inscripción, una circunstancia que reforzaría el probable origen foráneo de C. Duccius Phoebus, cuyo cognomen griego podría indicar también que nos encontraríamos ante un liberto o ante un descendiente de libertos. ${ }^{169}$

\begin{tabular}{|c|c|c|c|c|c|c|}
\hline Onomástica & Cron. & Origo & Tribu & Status & Cursus honorum & Referencia \\
\hline $\begin{array}{c}\text { Caius } \\
\text { Duccius } \\
\text { Phoebus }\end{array}$ & $\begin{array}{l}\text { Segunda } \\
\text { mitad s. I } \\
\text { d.C. }\end{array}$ & $\begin{array}{c}¿ \text { ¿Gallia } \\
\text { Narbonensis? }\end{array}$ & & $\begin{array}{c}\text { Libertus } \\
\text { / civis } \\
\text { Romanus }\end{array}$ & & $A E$ 1994, 841 \\
\hline $\begin{array}{c}\text { Titus } \\
\text { Pompeius } \\
\text { Albinus }\end{array}$ & $\begin{array}{l}\text { Siglo I d.C. } \\
\text { Años 60-64 } \\
\text { d.C. }\end{array}$ & Domo Vienna & Tromentina & $\begin{array}{c}\text { Eques } \\
\text { Romanus }\end{array}$ & $\begin{array}{l}\text { Duumvir iure } \\
\text { dicundo; trib. } \\
\text { militum leg. } \\
\text { VI Victricis; } \\
\text { adiutor T. Decidi } \\
\text { Domitiani } \\
\text { procuratoris } \\
\text { Caesaris Augusti }\end{array}$ & $A E 1935,5$ \\
\hline
\end{tabular}

Tabla 6. Inmigrantes de origen galo documentados en Augusta Emerita

\section{Conclusiones}

Desde su misma fundación Augusta Emerita fue una ciudad de inmigrantes. Sus inicios estuvieron marcados por el asentamiento de los veteranos itálicos de las legiones $V$ Alaudae y $X$ Gemina. Con posterioridad, su designación como capital provincial favoreció su conversión en un importante centro receptor de población. $\mathrm{La}$ mayoría de esos inmigrantes procedían de los territorios hispanos, ${ }^{170}$ aunque también fueron muchos los que llegaron desde las provincias extrapeninsulares, como hemos podido observar. En total hemos reunido en este trabajo 40 inscripciones que aluden a 44 individuos de origen no hispano. En el gráfico $\mathbf{n}^{\mathbf{0}} \mathbf{1}$ observamos que la mayor parte de ellos procedían de las provincias occidentales del Imperio (38 sobre 44, $86,3 \%)$ y, singularmente, de Italia. Por el contrario, son minoría los inmigrantes de origen oriental, que ascienden a 6 casos $(13,63 \%)$.

\footnotetext{
166 AE 1994, 841.

167 CIL XII 551.

168 RIB 673.

169 Solin 1982, 283 y 1370; Navarro Caballero - Ramírez Sádaba 2003, 163.

170 Haley 1986, 186-193; Edmondson 2004, 321-368.
} 


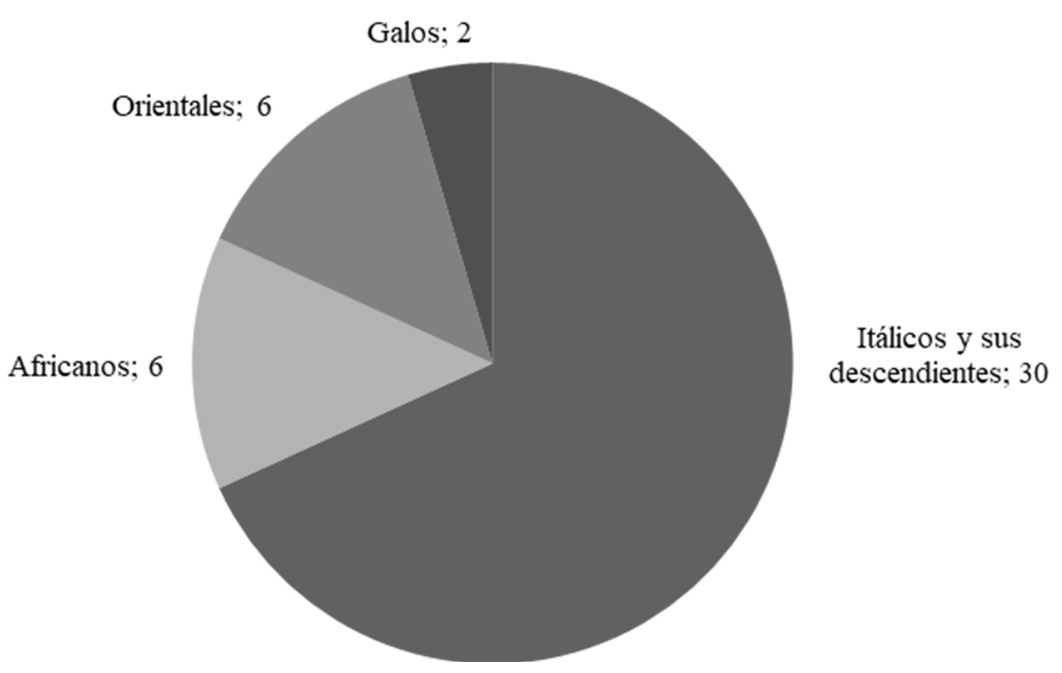

Gráfico 1. Distribución por origen de los individuos estudiados

Cronológicamente la movilidad estudiada se distribuye de forma desigual (gráfico $\mathbf{n}^{\mathbf{0}}$ 2). El momento de mayor impacto demográfico corresponde a la fundación colonial, algo lógico si tenemos en cuenta que la deductio habría traído consigo la conformación de un cuerpo cívico compuesto por entre 3.000 y 4.000 colonos, de origen mayoritariamente itálico. Con posterioridad, la llegada de inmigrantes no hispanos se reduce notablemente y se distribuye de forma más o menos homogénea entre los siglos I-III d.C., siendo la primera centuria el periodo más destacado.

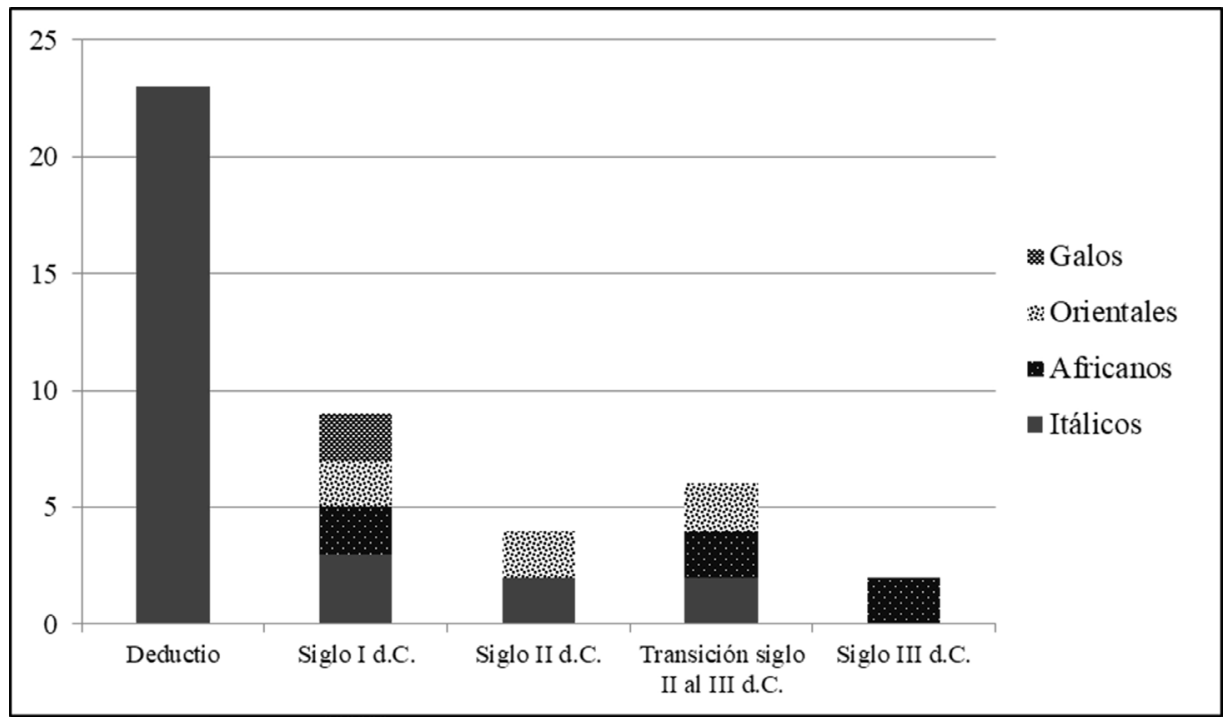

Gráfico 2. Distribución cronológica de la documentación epigráfica estudiada

Otras consideraciones que podemos realizar tienen que ver con la distribución por sexos o con el status jurídico de los inmigrantes estudiados. En relación a la 
primera destaca el claro predominio masculino de esta muestra, ya que 39 de los 44 personajes analizados, es decir, un $88,63 \%$, son hombres, mientras que tan sólo documentamos 5 mujeres (11,36\%). Un desequilibrio similar se constata en relación al status jurídico, donde podemos observar que la inmigración estudiada estuvo protagonizada mayoritariamente por ciudadanos romanos, cuyo número asciende a 36 casos $(81,81 \%)$.

El último aspecto que nos gustaría comentar tiene que ver con el papel jugado por estos inmigrantes en su nueva ciudad. A diferencia de lo que observamos en la epigrafía de varias colonias de la Baetica y la Citerior, ${ }^{171}$ ninguno de los colonos documentados en Augusta Emerita acredita el ejercicio de las magistraturas locales. Tampoco ninguno de los inmigrantes posteriores accedió a posiciones de poder en la colonia, una circunstancia que sí se produjo en ciudades como Barcino o Tarraco. ${ }^{172}$ Al contrario, la mejor forma de integración en la vida civil de estos inmigrantes fue a través del matrimonio y de la formación de una familia, circunstancia que se refleja sobre todo en las dedicatorias funerarias de los veteranos militares, que fueron homenajeados por sus esposas, como ocurrió con el beneficiarius $C$. M(- - ) Zosimus, o por sus hijos, como podemos observar en las inscripciones de P. Cincius Rufus y de L. Licinius Setianus. De igual modo, la formalización de un vínculo matrimonial con mujeres locales debió haber sido el mejor mecanismo de retorno a la vida civil para los primeros colonos itálicos. Así lo constatamos en la inscripción de C. Voconius, casado con Caecilia Anus, probablemente una mujer de origen indígena. Con ella tuvo dos hijos que honraron la memoria de su padre erigiendo una sepultura familiar donde fueron grabados los praemia obtenidos por Voconius durante su carrera militar.

\section{Referencias bibliográficas}

Abascal Palazón, J. M. (1994): Los nombres personales en las inscripciones latinas de Hispania (=Anejos de Antigüedad y Cristianismo II), Murcia.

Albertos Firmat, M L . (1966): La onomástica personal primitiva de Hispania: Tarraconense y Baetica (=Publicaciones del Colegio trilingüe de la Universidad de Salamanca. Theses et studia philologica Salmanticensia 13), Salamanca.

Alföldy, G. (1991): “Epigraphica Hispanica XIII. Eine inschrift aus Emerita Augusta: Rätsel oder steinmetzirrtum?", ZPE 87, 168-172.

Barrera Antón, J. L. de la (1988): "Un secutor en la arena emeritense", Anas 1, 121-124.

Beltrán Fortes, J. (2013): “Greco-orientales en la Hispania republicana e imperial a través de las menciones epigráficas”, [en] $\mathrm{M}^{\mathrm{a}} \mathrm{Paz}$ de Hoz - G. Mora (eds.), El Oriente griego en la Península Ibérica: epigrafia e historia (=Publicaciones del Gabinete de Antigüedades de la Real Academia de la Historia. Bibliotheca Archaeologica Hispanica 39), Madrid, 185-204. Bendala Galán, M. (1972): "Los llamados "Columbarios" de Mérida", Habis 3, 223-253. Brunt, P. A. (1971): Italian Manpower (225 B.C.-A.D. 14), Oxford.

Canto, A.

(1989): “Colonia Iulia Augusta Emerita: consideraciones en torno a su fundación y territorio", Gerión 7, 149-205.

171 Ortiz Córdoba, 2020a, 41-67; 2020c, 987-992; 2021, 512-516.

172 Ortiz Córdoba, 2020b, 294-302. 
(1990): "Las tres fundaciones de Augusta Emerita", [en] W. Trillmich - P. Zanker (coords.), Stadtbild und ideologie. Die Monumentalisierung hispanischer Städte zwischen Republik und Kaiserzeit. Kolloquium in Madrid, vom 19. bis 23. Oktober 1987 (=Bayerische Akademie der Wissenschaften. Philosophisch-Historische Klasse 103), Madrid, 289-298.

Carande Herrero, R. (2011): "Reflexiones sobre un presunto commaticum de Mérida. Nueva reconstrucción y propuesta alternativa”, [en] R. Carande Herrero - Q. López-Cañete (eds.), Pro tantis redditur: homenaje a Juan Gil en Sevilla, Zaragoza, 235-244.

Ceballos Hornero, A. (2004): Los espectáculos en la Hispania romana: la documentación epigráfica (=Cuadernos Emeritenses 26), Mérida.

Conway, R. S. (1967): The italic dialects, Cambridge.

Delgado Molina, P. A. (2017): "Excavación del área funeraria situada al NE de Augusta Emerita. Intervención arqueológica realizada en los terrenos de la ampliación del polígono industrial Reina Sofía", Mérida. Excavaciones arqueológicas 2006-2008, Memoria 12/2, 547-577.

Demougin S. (1992): Prosopographie des chevaliers romains julio-claudiens (43 av. J.-C. 70 ap. J.-C.), (=Publications de l'École française de Rome 153), Roma.

Edmondson, J.

(2000): "Conmemoración funeraria y relaciones familiares en Augusta Emerita", [en] Gorges - Nogales Basarrate (coords.), 2000, 299-327.

(2001a): "Conmemoración funeraria y contexto social", [en] Edmondson - Nogales Basarrate - Trillmich (2001), 75-94.

(2001b): "Catálogo", [en] Edmondson - Nogales Basarrate - Trillmich (2001), 113-189.

(2004): "Inmigración y sociedad local en Augusta Emerita, 25 a.C.-250 d.C.", [en] J.-G.

Gorges - E. Cerrillo - T. Nogales Basarrate (eds.), V Mesa Redonda Internacional sobre Lusitania Romana: las comunicaciones, Madrid, 321-368.

(2006): Granite Funerary Stelae from Augusta Emerita (=Monografías emeritenses 9), Mérida.

(2010): "Vétérans et société locale dans la colonie d'Augusta Emerita (25 av. J.-C. - 200 apr. J.-C.)", [en] Gorges - Nogales Basarrate (eds.), 2010, 211-251

(2018): "La formación de una sociedad colonial en Augusta Emerita", [en] T. Nogales - N. Barrero (eds.), La fundación de Augusta Emerita y los orígenes de Lusitania (=Monografías emeritenses 11), Mérida, 54-84.

Edmondson, J. - Hidalgo Martín, L. A. (2007): "Hallazgo de dos epitafios de veterani en Mérida: vidas paralelas de dos soldados Augustani (emeritenses) a finales del siglo I d.C.", Mérida. Excavaciones arqueológicas 2004, Memoria 10, 479-507.

Edmondson, J. - Nogales Basarrate, T. - Trillmich, W. (2001): Imagen y Memoria. Monumentos funerarios con retratos en la Colonia Augusta Emerita (=Publicaciones del Gabinete de Antigüedades de la Real Academia de la Historia. Bibliotheca Archaeologica Hispanica 10. Monografías emeritenses 6), Madrid.

Faria, A. M. (1999): “Colonização e municipalização nas províncias hispano-romanas: reanálise de alguns casos polémicos", Revista Portuguesa de Arqueologia 2/2, 29-50.

Forni, G.

(1976): "La tribu Papiria di Augusta Emerita", [en] A. Blanco Freijeiro (ed.), Augusta Emerita. Actas del Bimilenario de Mérida, Madrid, 33-42.

(1982): "La popolazione di Augusta Emerita", [en] Homenaje a Sáenz de Buruaga, Madrid, 69-84.

Gallego Franco, H. (1997): “Pannonios en Hispania romana”, Hispania Antiqua 21, 341-362. 
García Iglesias, L.

(1972): La epigrafia romana de Augusta Emerita, Tesis doctoral, Universidad Complutense de Madrid (=ERAE).

(1973): "Los judíos en la España romana", Hispania Antiqua 3, 331-366.

García y Bellido, A.

(1957): "El culto a Dea Caelestis en la Península Ibérica", BRAH 140, 451-485.

(1959): "El elemento forastero en Hispania romana", BRAH 144, 119-154.

(1960): "Némesis y su culto en España", BRAH 147, 119-147.

(1967): Les religions orientales dans l'Espagne Romaine (=Études préliminaires aux religions orientales dans l'Empire romain 5), Leiden (https://doi.org/10.1163/ 9789004296138).

Gómez Santa Cruz, J. (2017): “Augusta Emerita y el territorio de la Praefectura regionis Turgaliensis en época augustea", Gerión 35, 499-522 (http://dx.doi.org/10.5209/ GERI.56159).

Gómez-Pantoja, J. L. (2009): Epigrafia anfiteatrale dell'Occidente Romano. VII. Baetica, Tarraconensis, Lusitania (=Vetera 17), Roma.

Gómez-Pantoja, J. L. - Castillo Sanz, F. J. (2004): "Una fórmula epigráfica fracasada: aera", [en] F. Cadiou - M. Navarro Caballero (eds.), La guerre et ses traces. Conflits et sociétés en Hispanie à l'époque de la conquête romaine (IIIe-Ier s.av. J.-C.), (=Ausonius Éditions. Mémoires 37), Bordeaux, 507-518.

Gorges, J.-G. - Nogales Basarrate, T. (coords.), (2000): Sociedad y cultura en la Lusitania romana: IV Mesa Redonda Internacional (=Serie Estudios Portugueses 13), Mérida.

Gorges, J.-G. - Nogales Basarrate, T. (eds.), (2010): Naissance de la Lusitanie romaine (I av. - I ap. J.C.) - Origen de la Lusitania romana (siglos I a.C. - I d.C.). VII Table Ronde internationale sur la Lusitanie romaine, Toulouse-Mérida.

Grüll, T. (2018): "Origo as identity factor in Roman epitaphs", [en] G. Cupcea - R. Varga (eds.), Social Interactions and Status Markers in the Roman World (=Archaeopress Roman Archaeology 37), Oxford, 139-150 (http://dx.doi.org/10.2307/j.ctv17db2p0.13).

Haley, E. W.

(1986): Foreigners in Roman Imperial Spain: investigations of geographical mobility in the spanish provinces of the Roman Empire (30 B.C. - A.D. 284), Ph. Diss., Columbia University, New York.

(1991): Migration and economy in Roman Imperial Spain (=Universitat de Barcelona. Aurea saecula 5), Barcelona.

Hernández Guerra, L.

(1999): Epigrafía romana de unidades militares relacionadas con Petavonium (Rosinos de Vidriales, Zamora). Estudio social, religioso y prosopográfico, Valladolid.

(2007): "Veterani et milites alieni in Hispania", Aquila Legionis 9, 37-76.

(2013): Los libertos de la Hispania romana. Situación jurídica, promoción social y modos de vida (=Ediciones Universidad de Salamanca. Estudios Históricos y Geográficos 155), Salamanca.

(2016): Inscripciones romanas de libertos hispanos (=Universidad de Valladolid. Historia y Sociedad 197), Valladolid.

Hidalgo Martín, L. A. - Edmondson, J. - Márquez Pérez, J. - Ramírez Sádaba, J. L. (2019):

Nueva Epigrafía Funeraria de Augusta Emerita. Tituli sepulcrales (ss. I-VII d.C.) y su contexto arqueológico (=Monografías Arqueológicas de Mérida. Memoria 1), Mérida $(=N E F A E)$.

Hoz, Ma P. de (2014): Inscripciones griegas de España y Portugal (=Publicaciones del 
Gabinete de Antigüedades de la Real Academia de la Historia. Bibliotheca Archaeologica Hispanica 40), Madrid.

Kajanto, I. (1982): The Latin cognomina (=Societas Scientiarum Fennica. Commentationes Humanarum Litterarum 36/2), Roma.

Keppie, L.

(1983): Colonisation and Veteran Settlement in Italy. 47-14 b.C., London.

(2000): “Mark Antony's Legions", [en] L. Keppie, Legions and Veterans. Roman Army Papers 1971- 2000 (=Mavors XII), Stuttgart, 75-96.

Kubitschek, J. W. (1972 [1889]): Imperium Romanum Tributim Discriptum, Roma.

Lassère, J.-M. (2005): Manuel d'épigraphie latine, Paris.

Lefebvre, S. (2006): "Les migrations des Africani en Péninsule Ibérique: quelle vérité?", [en] A. Caballos Rufino - S. Demougin (eds.), Migrare. La formation des élites dans l'Hispanie Romaine (=Ausonius Éditions. Études 11), Bordeaux, 101-203.

Le Bohec, Y. (ed.), (2000): Les légions de Rome sous le Haut Empire. Actes du Congrès de Lyon (17-19 septembre 1998), Lyon, 3 vols.

Le Roux, P.

(1977): "Une inscription fragmentaire d'Augusta Emerita de Lusitanie à la lumière des Histoires de Tacite", Chiron 7, 283-289.

(1992): "L'armée romaine sous les Sévères", ZPE 94, 261-268.

(2000): “Legio VII Gemina (pia) Felix", [en] Le Bohec (ed.), 2000, vol. 1, 383-396.

Le Roux, P. - Ramírez Sádaba, J. L. (2009): "Un nuevo testimonio del ala miliaria de Mauretania Caesariensis en Augusta Emerita", [en] Espacios, usos y formas de la epigrafia Hispana en épocas Antigua y Tardoantigua: homenaje al Dr. Armin U. Stylow (=Anejos de AEspA XLVIII), Madrid, 297-306.

Malone, S. (2005): Legio XX Valeria Victrix: a prosopographical and historical study, $\mathrm{PhD}$ Thesis, University of Nottingham.

Mangas Manjarrés, J. (1971): Esclavos y libertos en la España romana (=Universidad de Salamanca. Acta Salmanticensia 62), Salamanca.

Marín Ceballos, Ma C. (1993): "Dea Caelestis en la epigrafía hispana", [en] II Congresso Peninsular de História Antiga, Coimbra, 825-846.

Márquez Pérez, J. (2006): Los Columbarios: arquitectura y paisaje funerario en Augusta Emerita (=Ataecina 2), Mérida.

Mateos Cruz, P. (2001): “Augusta Emerita. La investigación arqueológica en una ciudad de época romana”, AEspA 74, 183-208 (http://dx.doi.org/10.3989/aespa.2001.v74.153).

Melchor Gil, E. (2006): “Corduba, caput provinciae y foco de atracción para las élites locales de la Hispania Ulterior Baetica", Gerión 24, 251-279.

Morillo Cerdán, Á. (2002): “Conquista y estrategia: el ejército romano durante el período augusteo y julio-claudio en la región septentrional de la Península”, [en] Á. Morillo Cerdán (coord.), Actas del I Congreso de Arqueología Militar Romana en Hispania (=Gladius, Anejos 5), Madrid, 67-93.

Navarro Caballero, M. (2000): "Notas sobre algunos gentilicios romanos de Lusitania: una propuesta metodológica sobre la emigración itálica", [en] Gorges - Nogales Basarrate (coords.), 2000, 281-297.

Navarro Caballero, M. - Ramírez Sádaba, J. L. (coords.), (2003): Atlas antroponímico de la Lusitania romana, Mérida-Burdeos.

Nogales Basarrate, $\mathrm{T}$.

(1997): El retrato privado en Augusta Emerita (=Colección Arte-arqueología 13), Badajoz, 2 vols. 
(2000): Espectáculos en Augusta Emerita (=Monografías Emeritenses 5), Badajoz.

Nogales Basarrate, T. - Álvarez Martínez, J. M. (2013): “Augusta Emerita: reflexiones acerca de sus primeros tiempos", [en] R. Cid López - E. García Fernández (eds.), Debita verba: estudios en homenaje al profesor Julio Mangas Manjarrés, Oviedo, vol. I, 53-73.

Ortiz Córdoba, J.

(2018): "Dinámicas migratorias y movimientos de población en Lusitania. El caso de Olisipo Felicitas Iulia", Anales de Arqueología Cordobesa 29, 115-122 (http://dx.doi. org/10.21071/aac.v29i0.10994).

(2019a): Las colonias romanas de Hispania y los movimientos de población, Tesis doctoral, Universidad de Granada.

(2019b): "De Gallia a Hispania. La inmigración gala en la Península Ibérica a través de las evidencias epigráficas", Hispania Antiqua 43, 151-201 (http://dx.doi.org/10.24197/ ha.XLIII.2019.155-201).

(2019c): "Africani en las colonias romanas de la Hispania Citerior (siglos I-II d.C.)", Cartagine. Studi e Ricerche 4, 1-22 (https://doi.org/10.13125/caster/3840).

(2020a): "Estudio de los inmigrantes de origen extrapeninsular asentados en Barcino a partir de las evidencias epigráficas (Siglos I-II d.C.)", Cuadernos de Historia 52, 41-67 (http://dx.doi.org/10.4067/S0719-12432020000100041).

(2020b): "La integración de los inmigrantes extrapeninsulares en la élite local de las colonias romanas de Hispania. Estudio de algunos casos", [en] G. Bravo - E. Sánchez Medina (eds.), Percepciones romanas del otro (=Signifer. Monografías y Estudios de Antigüedad Griega y Romana 58), Madrid, 285-309.

(2020c): "Alieni in Colonia Iulia Urbs Triumphalis Tarraco: desde la fundación de la colonia hasta la promulgación de la Constitutio Antoniniana", Latomus, 79/4, 980-1027. (2021): "La formación de las sociedades coloniales en la Hispania Meridional", [en] J. Mangas Manjarrés - A. Padilla Arroba (eds.), Gratias tibi agimus. Homenaje al Profesor Cristóbal González Román, Granada, 507-530.

Palao Vicente, J. J.

(1998): "La participación de Africani en la Legio VII Gemina", Iberia 1, 145-166.

(2006): Legio VII Gemina (Pia) Felix. Estudio de una legión romana (=Ediciones Universidad de Salamanca. Estudios Históricos y Geográficos 136), Salamanca.

Pardo Anta, $\mathrm{M}^{\mathrm{a}} \mathrm{T}$. (2017): La sociedad emeritense altoimperial documentada en estelas y placas funerarias (=Cuadernos Emeritenses 34), Mérida.

Paredes Martín, E. (2018): "Un posible veterano de la legio V Alaudae y la fundación de Augusta Emerita: en torno a MNAR no inv., 30333”, Aquila Legionis 21, 107-119.

Perea Yébenes, S. (2000): “Hispania y la Legio XX”, [en] Le Bohec (ed.), 2000, vol. II, 581587.

Pflaum H. G. (1978): Les fastes de la province de Narbonnaise (=Gallia, Suppl. 30), Paris.

Ramírez Sádaba, J. L.

(1993): "Panorámica religiosa de Augusta Emerita", [en] M. Mayer - J. Gómez Pallarés (coords.), Religio deorum: actas del coloquio internacional de epigrafía "Culto y sociedad en Occidente", Sabadell, 389-398.

(1994-1995): "Estelas de granito inéditas del M.N.A.R. (Museo Nacional de Arte Romano) de Mérida", Anas 7-8, 257-268.

(1995): "Epigrafía del anfiteatro romano de Mérida", [en] Bimilenario del anfiteatro romano de Mérida. Coloquio internacional el anfiteatro en la Hispania Romana, Mérida, 285-299.

(2008): “La reconstrucción de las estructuras socioeconómicas y culturales a través de la 
epigrafía", [en] C. M. Cabanillas Nuñez - J. A. Calero Carretero (coords.), Actas de las V y VI Jornadas de Humanidades Clásicas, Almendralejo, 71-84.

(2009): "Nuevo commaticum hallado en Mérida", [en] X. Gómez i Font - C. Fernández Martínez - J. Gómez Pallarès (eds.), Literatura epigráfica. Estudios dedicados a Gabriel Sanders, Zaragoza, 279-289.

(2010): "La fundación de Augusta Emerita: primeras manifestaciones públicas y privadas", [en] Gorges - Nogales Basarrate (eds.), 2010, 319-335.

Recio Veganzones, A. - Curbera, J. (1996): "Los partidos triunfantes del franciscano Juan Mateo Reyes Ortiz de Tovar y su valor en la antigua epigrafía extremeña", Anas 9, 7-20. Rémy, B. - Ferber, E. (1991): "Une inscription de la cité de Vienne retrouvée (CIL XII 2327)", Revue archéologique de Narbonnaise 24, 267-270 (https://doi.org/10.3406/ ran.1991.1389).

Rodríguez González, J. (2001): Historia de las legiones romanas (=Signifer. Monografías y Estudios de Antigüedad Griega y Romana 4), Madrid.

Roldán Hervás, J. M. (1974): Hispania y el ejército romano. Contribución a la historia social de la España antigua (=Acta Salmanticensia 76), Salamanca.

Salomies, O. (1987): Die römischen Vornamen. Studien zur römischen Namengebung (=Commentationes Humanarum Litterarum 82), Helsinki.

Saquete Chamizo, J. C. (1997): Las élites sociales de Augusta Emerita (=Cuadernos Emeritenses 13), Mérida.

Saquete Chamizo, J. C. - Márquez Pérez, J. (1993): "Nuevas inscripciones romanas de Augusta Emerita: la necrópolis del Disco", Anas 6, 51-74.

Schulze, W. (1966): Zur Geschichte lateinischer Eigennamen, Berlin.

Solin, H.

(1982): Die griechische Personennamen in Rom. Ein Namenbuch, Berlin-New York.

(1983): "Juden und Syrer im westlichen Teil der römischen Welt. Eine ethnischdemographische Studie mit besonderer Berücksichtigung der sprachlichen Zustände", $A N R W$ II, 29/2, 587-589 (https://doi.org/10.1515/9783110847031-003).

(2014): “Analecta epigraphica CCXCII-CCCV", Arctos. Acta Philologica Fennica 48, 347-413.

Solin, H. - Salomies, O. (1988): Repertorium nominum gentilium et cognominum Latinorum, Hildesheim.

Stylow, A. U. - Ventura Villanueva, Á. (2009): "Los hallazgos epigráficos”, [en] R. Ayerbe Vélez - T. Barrientos Vera - F. Palma García (eds.), El Foro de Augusta Emerita. Génesis y evolución de sus recintos monumentales (=Anejos de AEspA 53), Mérida, 453-523.

Ventura Villanueva, Á. (2009): "Fasti Duovirales Coloniae Augustae Emeritae: reflexiones sobre la concepción, gestación y nacimiento de la ciudad de Mérida", ZPE 170, 215-246.

Wiegels, R.

(1976): "Zum Territorium der augusteischen Kolonie Emerita", Madrider Mitteilungen $176,258-284$.

(1985): Die Tribusinschriften des römischen Hispanien. Ein Katalog (=Madrider Forschungen XIII), Berlin.

Wierschowski, L. (2001): Fremde in Gallien - "Gallier" in der Fremde. Die epigraphisch bezeugte Mobilität in, von und nach Gallien vom 1. bis 3. Jh. n. Chr. (Texte- Übersetzungen - Kommentare), (=Historia, Einzelschriften 159), Stuttgart. 